\title{
Pathways for Conformational Interconversion of Calix[4]arenes
}

\author{
Stefan Fischer, ${ }^{\dagger}$ Peter D. J. Grootenhuis, ${ }^{\S}$ Leo C. Groenen, ${ }^{\ddagger}$ Willem P. van Hoorn, ${ }^{\ddagger}$ \\ Frank C. J. M. van Veggel, ${ }^{\ddagger}$ David N. Reinhoudt, ${ }^{\ddagger}$ and Martin Karplus ${ }^{*, \uparrow}$
}

\author{
Contribution from the Department of Chemistry, Harvard University, 12 Oxford Street, \\ Cambridge, Massachusetts 02138, Laboratory of Organic Chemistry, University of Twente, \\ P.O. Box 217, 7500 AE Enschede, The Netherlands, and N.V. Organon International, \\ P.O. Box 20, 5340 BH Oss, The Netherlands
}

Received June $27,1994^{\otimes}$

\begin{abstract}
Conformational optimization and reaction path calculations are performed on $\left[1_{4}\right]$ metacyclophane $3 \mathbf{a}$ and calix[4]arenes 1a and $\mathbf{2 b}$ using the CHARMM force field. For each of these compounds, a comprehensive search for all stable conformers was followed by an exhaustive exploration of the several hundred possible pathways between these conformers. The method employed for finding the reaction paths, Conjugate Peak Refinement, proved to be robust and reliable, allowing the connectivity of the complex potential energy surfaces to be charted. The relative stability of the four characteristic conformers agrees with experimental NMR data, except for the Cone form of $2 \mathbf{b}$. The pathways for Cone inversion in $\left[1_{4}\right]$ metacyclophane $3 \mathrm{a}$ show no preference for a pathway via the $1,2 \mathrm{Alt}$ or the $1,3 \mathrm{Alt}$ conformers. The conformational entropy corrected energy barriers $\Delta E^{\ddagger}$ conf are 3.1 and $3.3 \mathrm{kcal} / \mathrm{mol}$, respectively. For 1a, a stepwise pathway via the 1,2Alt conformer is found to be preferred for the Cone $\rightarrow$ inverted-Cone conversion. The rate-limiting step is the transition from Cone to Paco, with a barrier of activation $\Delta E_{\text {conf }}^{\ddagger}=14.5 \mathrm{kcal} / \mathrm{mol}$, comparable to the experimental $\Delta H^{*}=14.2 \mathrm{kcal} / \mathrm{mol}$. Conversion from the key Paco intermediate to the other characteristic conformers was investigated in detail in $\mathbf{2 b}$. The $\Delta E^{\ddagger}{ }_{\text {pot }}$ values for the conversion from the most stable Paco to Cone, 1,2Alt, and 1,3Alt conformers are 19.6, 20.2, and $18.2 \mathrm{kcal} / \mathrm{mol}$ respectively, in qualitative agreement with the relative rates deduced from 2D EXSY NMR. Paths for the transition from inward to outward orientation of the methoxy moieties of $\mathbf{2 b}$ are calculated. The corresponding activation barriers for the rotation of a methoxy group are in the $6-8 \mathrm{kcal} / \mathrm{mol}$ range, consistent with the upper bound obtained from the NMR time scale.
\end{abstract}

\section{Introduction}

Calix[4]arenes are macrocyclic compounds which consist of four phenol rings connected via methylene bridges located ortho to the hydroxyl groups. The rings cannot be coplanar and they adopt an orientation that makes the molecule appear like a cup or a chalice. They are being used increasingly in supramolecular chemistry as building blocks for larger molecules that are designed for the complexation of cations or neutral molecules. ${ }^{1}$ One interesting property of calix[4]arenes is that they have four characteristic nonplanar conformations, designated as the Cone, the partial Cone (Paco), the 1,2-alternate (1,2Alt), and the 1,3alternate (1,3Alt) (see Figure 1). Several studies have been published in which the relative stability of the calix[4]arene conformations has been calculated with molecular mechanics, ${ }^{2-4}$ but the relative stability of the four coiformations of calix[4]arenes 2 in $\mathrm{CDCl}_{3}$ found by $\mathrm{NMR}^{4 a, 5-7}$ was not reproduced

\footnotetext{
Harvard University.

$\$$ University of Twente.

$\S$ N.V. Organon International.

$\otimes$ Abstract published in Advance ACS Abstracts, December 1, 1994.

(1) (a) Gutsche, C. D. Calixarenes; Royal Society of Chemistry: Cambridge, 1989. (b) Calixarenes. A versatile Class of Compounds; Vicens, J., Böhmer, V., Eds.; Kluwer Academic Publishers: Dordrecht, The Netherlands, 1991. (c) Groenen, L. C.; Reinhoudt, D. N. Supramolecular Chemistry; Balzani, V., de Cola, L., Eds.; Kluwer Academic Publishers: Dordrecht, The Netherlands, 1991; pp 51-70.

(2) Grootenhuis, P. D. J.; Kollman, P. A.; Groenen, L. C.; Reinhoudt, D. N.; van Hummel, G. J.; Ugozzoli, F.; Andreetti, G. D. J. Am. Chem. Soc. 1990, 112, 4165-4176.
}

(3) Royer, J.; Bayard, F.; Decoret, C. J. Chim. Phys. 1990, 87, 16951700 .

(4) (a) Harada, T.; Rudziňski, J. M.; Shinkai, S. J. Chem. Soc., Perkin Trans. 2 1992, 2109-2115. (b) Harada, T.; Rudziňski, J. M.; Osawa, E.; Shinkai, S. Tetrahedron 1993, 49, 5941-5954.

(5) Iwamoto, K.; Araki, K.; Shinkai, S. J. Org. Chem. 1991, 56, 49554962 . exactly. Grootenhuis et al. ${ }^{2}$ used MACROMODEL ${ }^{8}$ (AMBER and MM2 force fields), MM2P, ${ }^{9}$ AMBER, ${ }^{10}$ and QUANTA/ $\mathrm{CHARMm}^{11}$ to calculate the relative stability of the four conformations of $\mathbf{2 c}$. The force fields showed pronounced differences, which were mainly caused by differences in the electrostatic energy. Only MM2P and QUANTA/CHARMm calculated the partial cone to have the lowest energy, in accord with the NMR data. Using the MM3 ${ }^{12}$ force field, Shinkai et $a l .{ }^{4}$ obtained good agreement for the relative stability of the four conformers of $\mathbf{2 a}$ and $\mathbf{2 b}$ between the NMR data and the calculated energies, including vibrational contributions estimated from normal modes.

Measurements with NMR spectroscopy have shown that calix[4]arenes with hydroxyl moieties at the lower rim (1) adopt the Cone conformation in $\mathrm{CDCl}_{3}$ solution, ${ }^{13}$ which is also the structure found in crystals. ${ }^{14}$ The stability of the Cone conformation is believed to be caused by a circular array of

(6) Gutsche, C. D.; Dhawan, B.; Levine, J. A.; No, K. H.; Bauer, L. J. Tetrahedron 1983, 39, 409-426.

(7) Groenen, L. C.; van Loon, J.-D.; Verboom, W.; Harkema, S.; Casnati A.; Ungaro, R.; Pochini, A.; Ugozzoli, F.; Reinhoudt, D. N. J. Am. Chem. Soc. 1991, 113, 2385-2392.

(8) MACROMODEL Version 1.5: Still, W. C.; Department of Chemistry, Columbia University, New York, 1987.

(9) MM2P(85): Sprague, J. T.; Tai, J. C.; Yuh, Y.; Allinger, N. L. J. Comput. Chem. 1987, 8, 581-603.

(10) AMBER 3.0: Singh, U. C.; Weiner, P. K.; Caldwell, J.; Kollman, P. A. University of California-San Francisco, 1987.

(11) QUANTA 2.1A: Polygen Corp., Waltham, MA

(12) (a) Allinger, N. L.; Yuh, Y. H.; Lii, J.-H. J. Am. Chem. Soc. 1989 111, 8551-8566. (b) Lii, J.-H.; Allinger, N. L. J. Am. Chem. Soc. 1989, $111,8566-8575$. (c) Lii, J.-H.; Allinger, N. L. J. Am. Chem. Soc. 1989, $111,8576-8582$.

(13) (a) Happel, G.; Mathiasch, B.; Kämmerer, H. Macromol. Chem. 1975, 176, 3317-3334. (b) Gutsche, C. D.; Bauer, J. J. Am. Chem. Soc. 1985, 107, 6052-6059. (c) Araki, K.; Shinkai, S.; Matsuda, T. Chem. Lett. $1989,581-584$. 

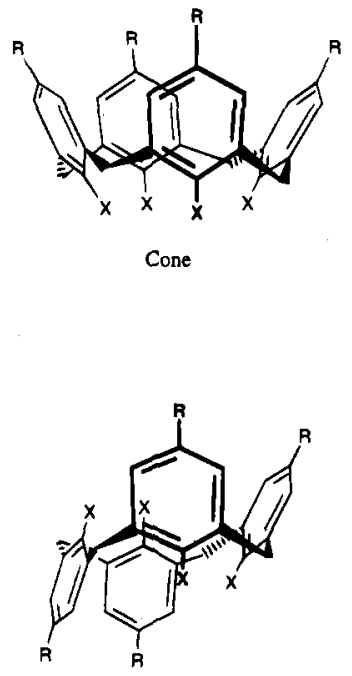

1,2-Altemate

(1,2Alt)
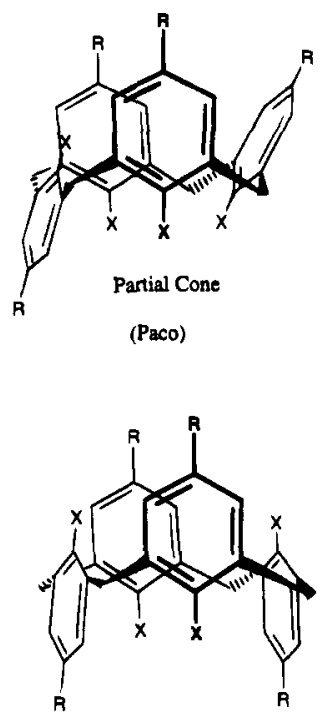

1,3-Altemate

(1,3Alt)

\begin{tabular}{l|ll} 
& $\mathbf{x}$ & $\mathbf{R}$ \\
\hline $\mathbf{1 a}$ & $\mathrm{OH}$ & $\mathrm{H}$ \\
$\mathbf{1 b}$ & $\mathrm{OH}$ & $\mathrm{Me}$ \\
$\mathbf{1 c}$ & $\mathrm{OH}$ & $\mathrm{i}-\mathrm{Pr}$ \\
$\mathbf{2 a}$ & $\mathrm{OMe}$ & $\mathrm{H}$ \\
$\mathbf{2 b}$ & $\mathrm{OMe}$ & t-Bu \\
$\mathbf{2 c}$ & $\mathrm{OMe}$ & $\mathrm{Me}$ \\
$\mathbf{3 a}$ & $\mathbf{H}$ & $\mathbf{H}$ \\
3b & $\mathrm{H}$ & t-Bu
\end{tabular}

Figure 1. The four characteristic conformers of [14]metacyclophanes and calix[4]arenes.

very strong hydrogen bonds, in which the $\mathrm{OH}$ groups at the lower rim act as both donors and acceptors. The calix[4]arenes 1 are still conformationally flexible, because the two equivalent Cone conformations (with the four oxygen atoms either all up or all down) can interconvert. Several mechanisms for interconversion have been proposed. One is a "broken-chain" mechanism, in which the array of H-bonds is broken and the $1,3 \mathrm{Alt}$ form is the intermediate; ${ }^{13 a}$ another is a "continuouschain" mechanism, in which the hydrogen bonds remain mostly intact and a skewed 1,2Alt-like intermediate is involved. ${ }^{136}$ Some authors have suggested that the interconversion of tetrahydroxycalix [4]arenes is a concerted process in which more than one phenol ring rotate simultaneously. ${ }^{13 a, c, 15}$ In all proposed mechanisms the hydroxyl moieties swing through the annulus, since the upper rim (bearing the $R$ groups in Figure 1) is too large to pass through the annulus.

The calix[4]arene derivatives 2 exist in $\mathrm{CDCl}_{3}$ solution at room temperature as a mixture of all four characteristic conformations, as determined by ${ }^{1} \mathrm{H}$ and $2 \mathrm{D}$ NMR measurements. ${ }^{4 a, 5-7}$ In decreasing order, the relative stability fo $\mathbf{2 b}$ is Paco (most stable) $>1,2 \mathrm{Alt}>$ Cone $>1,3 \mathrm{Alt}$. The conformers interconvert rapidly, with the Paco conformer as the key intermediate, as indicated by 2D EXSY NMR spectra showing cross-peaks for Paco/Cone and Paco/1,3Alt conformations. ${ }^{7,16}$ Each of the other three conformations can be formed from the Paco conformation by the rotation of only one anisole ring. The methoxy moiety passes through the annulus during the ringflips. Conformational interconversion is no longer possible at room temperature when the methoxy moieties in $\mathbf{2 b}$ are replaced by ethoxy groups. Solvent effects in $\mathrm{CDCl}_{3}$ play a minor role, although compounds $\mathbf{2 b}$ and $\mathbf{3 b}$ are capable of complexing solvent molecules in the cavity formed by the four $p$-tert-butyl groups in the Cone form, as seen in the X-ray crystal structures of complexes with toluene, ${ }^{14} \mathrm{MeCN},{ }^{17}$ or $p$-phenylcalix[4]arene complexed with $\mathrm{CHCl}_{3}{ }^{18}$

The $\left[1_{4}\right]$ metacyclophanes 3 have recently been synthesized. ${ }^{19,20}$ These compounds are more flexible than either 1 or 2. No single characteristic conformation could be shown to be

(14) Andreetti, G. D.; Ungaro, R.; Pochini, A. J. Chem. Soc., Chem. Commun. 1979, 1005-1007.

(15) Groenen, L. C.; Steinwender, E.; Lutz, B. T. G.; van der Maas, J. H.; Reinhoudt, D. N. J. Chem. Soc., Perkin Trans. 2 1992, 1893-1898.

(16) van Loon, J.-D.; Groenen, L. C.; Verboom, W.; Wijmenga, S. S. Reinhoudt, D. N. J. Am. Chem. Soc. 1991, 113, 2378-2384. the most stable by NMR in $\mathrm{CDCl}_{2} \mathrm{~F}$ solution. Because [1 $\left.{ }_{4}\right]-$ metacyclophanes have the same skeleton as the calix[4]arenes, investigation of $\left[1_{4}\right]$ metacyclophanes can yield insight into the influence of the lower rim substitute ( $X$ in Figure 1 ) and the skeleton on the properties of calix [4]arenes. ${ }^{4 b, 21}$

Recently, an algorithm has been developed for finding reaction pathways and transition states involving many degrees of freedom. ${ }^{22}$ This algorithm, called Conjugate Peak Refinement (CPR), yields a series of true saddle points which are connected to one another through minimum energy paths composed of a string of structures. The resulting path forms a continuous reaction coordinate between a given reactant and a given product. Unlike a trajectory obtained from molecular dynamics, which includes many fluctuations uncorrelated to the progress of the reaction, the reaction trajectory involves only the minimal amount of necessary motions. In the lowtemperature limit, this sequence of conformations is the most probable path. At normal temperatures, it is likely to be a good approximation to the path obtained by averaging over the dynamic pathways, particularly if the conformational change is dominated by the energy rather than by entropy. CPR is currently the only available method for finding adiabatic reaction paths that is fully automated and reliable for systems that have complex energy surfaces involving a very large number of degrees of freedom. The CPR algorithm is integrated in the CHARMM $^{23}$ program and has been successfully applied to the tyrosine ring-flip in BPTI, ${ }^{24}$ to the closure of the lid over the catalytic site of triosephosphate isomerase, ${ }^{25}$ and to the mechanism of rotamase catalysis by FKBP. ${ }^{26}$ Here, we use the CPR algorithm to exhaustively explore the conformational intercon-

(17) McKervey, M. A.; Seward, E. M.; Ferguson, G.; Ruhl, B. L. J. Org. Chem. 1986, 51, 3581-3584.

(18) Juneja, R. K.; Robinson, K. D.; Johnson, C. P.; Atwood, J. L. J. Am. Chem. Soc. 1993, 115, 3818-3819.

(19) (a) Ting, Y.; Verboom, W.; Groenen, L. C.; van Loon, J.-D.; Reinhoudt, D. N. J. Chem. Soc., Chem. Commun. 1990, 1432-1433. (b) Goren, Z.; Biali, S. E. J. Chem. Soc., Perkin Trans. 1 1990, 1484-1487. (c) Grynszpan, F.; Goren, Z.; Biali, S. E. J. Org. Chem. 1991, 56, 532536. (d) Grynszpan, F.; Biali, S. F. Tetrahedron Lett. 1991, 32, 51555158. 5658.

(20) McMurry, J. E.; Phelan, J. C. Tetrahedron Lett. 1991, 32, 5655-

(21) Jaime, C.; de Mendoza, J.; Prados, P.; Nieto, P. M.; Sánchez, C. J. Org. Chem. 1991, 56, 3372-3376.

(22) Fischer, S.; Karplus, M. Chem. Phys. Lett. 1992, 194, 252-261.

(23) Brooks, B. R.; Bruccoleri, R. E.; Olafson, B. D.; States, D. J.; Swaminathan, S.; Karplus, M. J. Comp. Chem. 1983, 4, 187-217. 
version in [1 $\left.{ }_{4}\right]$ metacyclophane $3 \mathbf{a}$ and in calix[4]arenes 1a and 2b. These compounds are representative of most compounds 1,2 , and 3 , because the nature of the upper rim substitutes has only a marginal effect on the total energy of the conformation. ${ }^{2}$ We propose detailed stepwise sequences for interconversion in [14]metacyclophanes 3 and in calix[4]arenes 1 and 2. The corresponding activation barriers of the conformational interconversion in calix [4]arene 1a enable us to distinguish between the reaction mechanisms proposed for interconversions in $1 .^{13,15}$ The energies of the transitions states in $\mathbf{2 b}$ are compared with kinetic data from ${ }^{1} \mathrm{H}$ and 2D NMR. Results in agreement with experiment are obtained. They provide new insights int the nature of the transitions and indicate that version 22 of the allhydrogen CHARMM parameter $\operatorname{set}^{27}$ is appropriate for calix[4]arenes.

\section{Methods}

Energy Minimizations. For compounds 1a and 3a, the four characteristic conformations were considered and minimized. For compounds $\mathbf{2 b}$, a systematic search with concomitant energy minimization of all possible in/out orientations of the methoxy groups in each of the four characteristic conformations was performed. The energies of the conformations were minimized by the Conjugate Gradient method and followed by the Newton-Raphson method until the root-meansquare (rms) value of the energy gradient was less than $0.0001 \mathrm{kcal}$ $\mathrm{mol}^{-1} \AA^{-1}$. For compound 1a, the influence of cooperative polarization of the hydroxyl groups was investigated by varying the charge separation across the $\mathrm{O}-\mathrm{H}$ bond. The bonded parameters, point charges, and van der Waals parameters were derived from a developmental version of the CHARMM parameters for the tyrosine and aliphatic amino acids side chains and for methyl acetate (see Appendix). A dielectric constant $\epsilon=1$ was used with no cut-off for the nonbonded interactions. This seems appropriate, since most studies are carried out in weakly polar solvents. All calculations were done with the CHARMM program. ${ }^{23}$

Reaction Path Calculations. The Conjugate Peak Refinement (CPR) algorithm ${ }^{22}$ searches for maxima along the adiabatic energy valley connecting two local minima on an energy surface. These maxima are refined to saddle points and represent the transition states of the reaction pathway between the two minima. The algorithm has been integrated to the CHARMM program ${ }^{23}$ in the TRAVEL module. The output of CPR consists of a series of $N$ intermediate structures (each given by its coordinate vector $\mathbf{r}_{i}$ ) along the reaction pathway from the reactant $\mathbf{r}_{0}$ to the product $\mathbf{r}_{N+1}$, including one or more saddle points. The one-dimensional reaction coordinate along this curvilinear path is given by

$$
\lambda_{i}=\sum_{j=0}^{i-1}\left|\mathbf{r}_{j+1}-\mathbf{r}_{j}\right|
$$

The path-scanning step size $\Delta \lambda$ (the only parameter of the CPR method which has a system-dependent optimal value) was set initially to $1 / 6$ of the rms difference between reactant and product coordinates. This step size is automatically reduced in TRAVEL until an optimum value is reached. ${ }^{24}$ The final value of $\Delta \lambda$ was $0.05 \AA$, except for the calculations on the polarized $\mathrm{O}-\mathrm{H}$ bonds, where it got reduced to 0.01 $\AA$. Presetting the optimum step size can save some computational overhead. The rms gradients of the saddle points were in the $10^{-6}$ $10^{-5} \mathrm{kcal} \mathrm{mol}^{-1} \AA^{-1}$ range. In the absence of an initial guess for transition intermediates, the CPR method as implemented in TRAVEL generates a first guess for the pathway by linear interpolation between

(24) Fischer, S. Curvilinear reaction coordinates of conformational change in macromolecules. Application to rotamase catalysis. Ph.D. Thesis, Harvard University, 1992.

(25) Joseph, D.; Fischer, S.; Karplus, M. In preparation.

(26) Fischer, S.; Michnick, S.; Karplus, M. Biochemistry 1993, 32, 13830-13837.

(27) (a) Smith, J. C.; Karplus, M. J. Am. Chem. Soc. 1992, 114, 801812. (b) Dunbrack, R. L., Jr.; Joseph, D.; Karplus, M. To be submitted for publication. (c) MacKerell, A.; Karplus, M.; et al. To be submitted for publication. the Cartesian coordinates of the reactant and the product. In a few cases, such an initial guess results in a path with some unlikely segments, for example in which a hydrogen passes through the aromatic ring. This problem is easily resolved by continuing the refinement after having excised the undesired segments from the path. After all the saddle points were fully refined by CPR, and for those paths shown here in the figures, the other path points were further relaxed into the adiabatic valleys of the energy by Synchronous Chain Minimization $(\mathrm{SCM}),{ }^{28}$ a path optimization method related to the procedure by Choi and Elber, ${ }^{29}$ but better behaved in systems with many degrees of freedom.

The pathways for compounds $1 \mathbf{a}$ and $\mathbf{3 a}$ were generated by calculating the following transitions: Cone $\rightarrow$ Paco, Paco $\rightarrow$ 1,2Alt, Paco $\rightarrow 1,3$ Alt, Cone $\rightarrow 1,2 \mathrm{Alt}$, Cone $\rightarrow 1,3 \mathrm{Alt}$, and Cone $\rightarrow$ inverted Cone (Cone'), all without initial intermediates. Concerted Cone $\rightarrow$ Cone' pathways in 1a were obtained by increasing the charge separation on the $\mathrm{OH}$ moiety. The Paco is the key intermediate for compound $\mathbf{2 b}$, therefore the following transitions were calculated for this compound: all Paco conformations to all Cone, 1,2Alt, and 1,3Alt conformations (conformations are described in Table 2). After the lowest-energy interconversion path was found from one characteristic conformation to the other, methyl rotation paths were calculated for each characteristic conformation, in order to find the complete lowest energy path from the ground state of each characteristic conformer to the ground state of every other characteristic conformer. Unless otherwise specified, the transition state energies given here are relative to the energy of the most stable conformer (global energy minimum) of $\mathbf{1 a}, \mathbf{2 b}$, or $\mathbf{3 a}$, respectively.

Hammond Postulate. According to Hammond, "If two states, as for example, a transition state and an unstable intermediate, occur consecutively during a reaction process and have nearly the same energy content, their interconversion will involve only a small reorganization of the molecular structures". Although the Hammond postulate was formulated for chemical reactions, it is likely to apply also to conformational transitions. Thus, the change in geometry during a conformational interconversion should correlate with the change in energy. The applicability of the postulate was tested by comparing the progress along the reaction coordinate $\lambda$ (taken relative to a given saddle point) to the change in the energy. For the structures $k$ along the path on each side $(k>0$ or $k<0)$ of the saddle point $(k=0)$, we define:

$$
\begin{gathered}
h_{k}=\left|\lambda_{k}-\lambda_{\text {saddle }}\right| \\
H_{k}=\operatorname{MAX}\left(h_{k}\right)-h_{k}
\end{gathered}
$$

To allow a direct comparison of the energy and $H_{k}$, the values $H_{k}$ are scaled so that the amplitude of the change in $H_{k}$ equals the energy barrier. $H_{k}$ is plotted as a function of $\lambda_{k}$ to show the correlation between changes in the energy and changes in the rms displacement of the atomic coordinates.

\section{Results}

(a) Geometry Optimizations. The minimized energies of the four characteristic conformers of compound 3a are listed in Table 1 . These results are very similar to those previously obtained with the MM3 force field. ${ }^{46}$ Calculations with the MMX force field ${ }^{20}$ and MM2 force field ${ }^{21}$ also resulted in Cone as the lowest energy conformation. The energy differences between conformers is small, with a maximum value of $1.9 \mathrm{kcal} /$ mol between the Cone and 1,3Alt conformers.

Also listed in Table 1 are the optimized energies of compound 1a, which are obtained when the four hydroxyls remain in the same orientation relative to their ring. It is the orientation that allows the formation of a circular array of four H-bonds in the Cone. The Cone is the lowest energy conformer, in accordance with ${ }^{1} \mathrm{H}$ NMR data in various solvents. ${ }^{13}$ Earlier molecular mechanics calculations $2.3,4 \mathrm{~b}$ have yielded the same energy order: Cone $<$ Paco $<1,2$ Alt $<1,3$ Alt. Recent calculations

(28) Fischer, S.: Karplus, M. In preparation.

(29) Choi, C.; Elber, R. J. Chem. Phys, 1991, 94, 751-760.

(30) Hammond, G. S. J. Am. Chem. Soc. 1955, 77, 334-338. 
Table 1. Energyf $(\mathrm{kcal} / \mathrm{mol})$ for the Characteristic Conformers of $\left[1_{4}\right]$ Cyclophane $3 a$ and of Calix[4]arene 1a

\begin{tabular}{lrrrrrrr}
\hline \multicolumn{1}{c}{ conf } & $\mathrm{MM}^{a}$ & $E_{\text {coval }}{ }^{b}$ & $E_{\text {vdw }}$ & $E_{\text {elec }}$ & $E_{\text {pot }}{ }^{c}$ & $n^{d}$ & $E_{\text {conf }^{f}}$ \\
\hline 3a & & & & & & & \\
Cone & 0.0 & 0.0 & 0.0 & 0.0 & 0.0 & 2 & 0.0 \\
Paco & 1.2 & 0.8 & 1.9 & -1.5 & 1.2 & 8 & 0.5 \\
1,2Alt & 1.8 & 1.3 & 2.3 & -1.8 & 1.8 & 4 & 1.5 \\
1,3Alt & 1.7 & 1.1 & 2.1 & -1.3 & 1.9 & 2 & 1.9 \\
1a & & & & & & & \\
Cone & 0.0 & 0.0 & 0.0 & 0.0 & 0.0 & 2 & 0.0 \\
Paco & 9.9 & 1.0 & -1.8 & 10.4 & 9.6 & 8 & 8.9 \\
1,2Alt & 11.7 & 2.9 & -2.1 & 11.0 & 11.8 & 4 & 11.5 \\
1,3Alt & 18.7 & 0.5 & -3.5 & 20.2 & 17.2 & 2 & 17.2 \\
\hline
\end{tabular}

${ }^{a}$ Potential energy from ref $4 \mathrm{~b} .{ }^{b} E_{\text {coval }}=E_{\text {bond }}+E_{\text {angle }}+E_{\text {urey }}+$ $E_{\text {dihe. }}{ }^{c} E_{\text {pot }}=E_{\text {coval }}+E_{\text {vdw }}+E_{\text {elec. }}{ }^{d} n$ is the conformational degeneracy of each conformer. ${ }^{e} E_{\text {conf }}=E_{\mathrm{pot}}-k T \ln (n)$, at $-30^{\circ} \mathrm{C}$. ${ }^{f}$ Energies are given relative to the minimum energy Cone form of the respective compound. Absolute energies, particularly the covalent terms, have little significance when empirical energy functions are used.

with the MM3 force field ${ }^{4 b}$ yielded very similar energy values (see Table 1). Four H-bonds are present in the Cone conformation, two in the Paco or the 1,2Alt, and none in the 1,3Alt. From Table 1, it can be seen that the relative stability of the conformations of $1 \mathrm{a}$ is essentially determined by the number of hydrogen bonds that can be formed. Each H-bond contributes to lower the electrostatic energy by about $5 \mathrm{kcal} / \mathrm{mol}$. Other molecular mechanics force fields vary in their ability to distinguish between the 1,2Alt ( 2 hydrogen bonds) and the 1,3 Alt ( 0 hydrogen bonds) conformers: the energy difference is $7.0 \mathrm{kcal} / \mathrm{mol}$ for $\mathrm{MM} 3,{ }^{4 \mathrm{~b}}$ but only $0.1 \mathrm{kcal} / \mathrm{mol}$ for $\mathrm{MM}^{2} \mathrm{P}^{3}$ and $1.3 \mathrm{kcal} / \mathrm{mol}$ for AMBER 3.0. ${ }^{2}$

The Cone, Paco, and 1,3Alt conformers of 1a are almost identical to the Cone, Paco, and 1,3Alt conformers of 3a. The rms differences in the positions of the C-atoms are only 0.1 , 0.1 , and $0.2 \AA$, respectively. The 1,2 Alt of $3 \mathrm{a}$ differs from the $1,2 \mathrm{Alt}$ of $1 \mathrm{a}$ ( $\mathrm{rms}$ difference $0.8 \AA$ ) by the fact that one benzyl ring is rotated away from the annulus. The small differences between the conformations of $1 \mathbf{a}$ and $3 a$ indicate that nearoptimal H-bonds can be formed in 1a without inducing extra strain in the skeleton of the [14]metacyclophane moiety.

Each of the four methoxy groups of the tetramethyl ether compound $\mathbf{2 b}$ can point either toward the center of the annulus (in) or toward the outside (out). For each of the four characteristic conformers of $\mathbf{2 b}$, a systematic search of all possible in/out orientations of the methoxy groups was performed. It was found that 28 out of the 31 possible conformations are stable. The corresponding local energy minima are listed in Table 2. The most stable conformer is Paco with one methoxy pointing inward. The variation in the potential energy for the various conformers is quite large, up to $27.7 \mathrm{kcal} / \mathrm{mol}$ above the Paco ground state. The highest energy conformers are found for the Cone and the Paco states when a majority of the methoxy groups point inward toward each other, resulting in structural distortions as indicated by the large contribution of $E_{\text {coval }}$ to the potential energy of these states. The 1,2Alt and the 1,3Alt states can better accommodate the inward pointing methoxy groups, since these are distributed on both sides of the annulus.

(b) Interconversion pathways. (i) Ring-Flips in [14]Metacyclophane 3a. The transition-state energies for the three saddle points connecting the Paco form to the Cone, 1,2Alt, and 1,3Alt conformers are listed in Table 3 . The energy profiles of the corresponding reaction paths are shown in Figure 2. From the connectivity chart in Figure 3A, it is apparent that the Cone $\rightarrow$ inverted Cone (Cone') conversion with the lowest energy barrier is via the 1,2Alt intermediate, with the rate-limiting step (in terms of energy barriers) being the Cone $\rightarrow$ Paco transformation, which has an activation barrier of $\Delta E_{\mathrm{pot}}^{4}=3.8 \mathrm{kcal} /$ mol. The energy barrier arises mainly from angle distortion
Table 2. Energy (kcal/mol) of the Conformers of Calix[4]arene 2b

\begin{tabular}{|c|c|c|c|c|c|c|}
\hline $\operatorname{conf}^{a}$ & $E_{\text {coval }}$ & $E_{\mathrm{vdW}}$ & $E_{\text {elec }}$ & $E_{\mathrm{pot}}$ & $n$ & $E_{\text {conf }}$ \\
\hline \multicolumn{7}{|l|}{ Paco } \\
\hline 0001 ABAA & 0.0 & 0.0 & 0.0 & 0.0 & 8 & 0.0 \\
\hline $0001 \sim$ AAAA & -7.8 & -0.1 & 9.0 & 1.1 & 8 & 1.1 \\
\hline $0001 \sim \mathrm{AAAB}$ & -5.4 & 0.5 & 6.1 & 1.2 & 8 & 1.2 \\
\hline $0001 \sim \mathrm{ABAB}$ & 2.6 & 1.2 & -1.7 & 2.1 & 8 & 2.1 \\
\hline $0001 \sim \mathrm{BAAA}$ & -3.6 & 0.0 & 5.8 & 2.2 & 16 & 1.9 \\
\hline $0001 \sim \mathrm{AABA}$ & 1.0 & 1.5 & -0.3 & 2.2 & 16 & 1.9 \\
\hline $0001 \sim \mathrm{BABA}$ & 2.0 & 0.2 & 1.7 & 3.9 & 8 & 3.9 \\
\hline 0001 BBAA & 8.7 & 1.6 & -1.9 & 8.4 & 16 & 8.1 \\
\hline $0001 \sim \mathrm{BABB}$ & 10.2 & 2.1 & -3.8 & 8.5 & 8 & 8.5 \\
\hline $0001 \sim \mathrm{ABBB}$ & 15.8 & 3.6 & -4.7 & 14.7 & 16 & 14.4 \\
\hline $0001 \sim \mathrm{BBBB}$ & 28.9 & 3.6 & -4.8 & 27.7 & 8 & 27.7 \\
\hline $0001 \sim \mathrm{BBBA}$ & & & & & 8 & unstable \\
\hline \multicolumn{7}{|l|}{$1,2 \mathrm{Alt}$} \\
\hline $0011 \sim \mathrm{ABAB}$ & -0.2 & 1.6 & -0.7 & 0.7 & 8 & 0.7 \\
\hline $0011 \sim \mathrm{AAAB}$ & -2.1 & 1.0 & 2.5 & 1.4 & 16 & 1.1 \\
\hline $0011 \sim \mathrm{ABBA}$ & 2.5 & 1.7 & -2.0 & 2.2 & 8 & 2.2 \\
\hline $0011 \sim$ AAAA & -4.2 & 1.7 & 9.3 & 6.8 & 4 & 7.1 \\
\hline 0011 BBBA & 7.3 & 4.4 & -2.0 & 9.7 & 16 & 9.4 \\
\hline $0011 \sim \mathrm{AABB}$ & 4.8 & 3.5 & 1.7 & 10.0 & 8 & 10.0 \\
\hline $0011 \sim \mathrm{BBBB}$ & & & & & 4 & unstable \\
\hline \multicolumn{7}{|l|}{$1,3 \mathrm{Alt}$} \\
\hline $0101 \sim$ AAAA & -7.8 & -2.0 & 10.3 & 0.5 & 2 & 1.2 \\
\hline $0101 \sim \mathrm{AABA}$ & -5.4 & -0.1 & 6.3 & 0.8 & 8 & 0.8 \\
\hline $0101 \sim \mathrm{AABB}$ & -0.9 & 1.8 & 0.4 & 1.3 & 8 & 1.3 \\
\hline 0101 BABA & -1.7 & -0.1 & 3.8 & 2.0 & 4 & 2.3 \\
\hline $0101 \sim \mathrm{ABBB}$ & 5.0 & 3.0 & -1.2 & 6.8 & 8 & 6.8 \\
\hline $0101 \sim \mathrm{BBBB}$ & 12.7 & 3.5 & -2.8 & 13.4 & 2 & 14.1 \\
\hline \multicolumn{7}{|l|}{ Cone } \\
\hline $0000 \sim \mathrm{AAAA}$ & -8.4 & 0.2 & 12.0 & 3.8 & 2 & 4.5 \\
\hline $0000 \sim \mathrm{AABA}$ & 2.1 & 2.0 & 1.0 & 5.1 & 8 & 5.1 \\
\hline $0000 \sim \mathrm{ABAB}$ & 6.1 & 1.9 & -0.6 & 7.4 & 4 & 7.7 \\
\hline $0000 \sim \mathrm{AABB}$ & 12.8 & 4.9 & -2.6 & 15.1 & 8 & 15.1 \\
\hline $0000 \sim \mathrm{ABBB}$ & 22.1 & 4.2 & -2.8 & 23.5 & 8 & 23.5 \\
\hline $0000 \sim \mathrm{BBBB}$ & & & & & 2 & unstable \\
\hline
\end{tabular}

${ }^{a}$ The digits in the names of conformations indicate which anisole ring is inverted. The letters indicate whether the methoxy group attached to each aromatic ring points outwards (A) or inwards (B). For example: 0001 AAAB is a Paco in which the methoxy group on the inverted aromatic ring points inwards. See also caption of Table 1.

Table 3. Energy ${ }^{a}(\mathrm{kcal} / \mathrm{mol})$ of the Transition State in Aromatic Ring-Flipping Reactions.

\begin{tabular}{lcrrrrr}
\hline \multicolumn{1}{c}{ reaction } & $E_{\text {coval }}^{\mp}$ & $E^{\mp}$ vdw & $E^{\mp}{ }_{\text {elec }}$ & $E^{\mp}{ }_{\text {pot }}$ & $n^{\mp}$ & $E_{\text {conf }}^{\mp}$ \\
\hline 3a & & & & & & \\
Cone $\rightarrow$ Paco & 3.0 & 2.9 & -2.1 & 3.8 & 8 & 3.1 \\
Paco $\rightarrow$ 1,2Alt & 2.0 & 2.4 & -1.8 & 2.6 & 16 & 1.6 \\
Paco $\rightarrow$ 1,3Alt & 3.0 & 3.0 & -2.0 & 4.0 & 8 & 3.3 \\
$1 \mathbf{1 a}$ & & & & & & \\
Cone $\rightarrow$ Paco & 6.5 & -0.4 & 9.1 & 15.2 & 8 & 14.5 \\
Paco $\rightarrow$ 1,2Alt & 4.7 & 0.9 & 9.1 & 14.7 & 16 & 13.7 \\
Paco $\rightarrow$ 1,3Alt & 6.2 & -1.6 & 18.2 & 22.8 & 8 & 22.1 \\
\hline
\end{tabular}

${ }^{a}$ Energies are relative to the Cone ground state of the respective compound (see also caption of Table 1).

$(2.4 \mathrm{kcal} / \mathrm{mol})$ and unfavorable van der Waals interactions ( 2.8 $\mathrm{kcal} / \mathrm{mol}$ ), which are compensated somewhat by favorable electrostatic interactions $(-2.1 \mathrm{kcal} / \mathrm{mol})$. The Cone $\rightarrow$ Cone $^{\prime}$ route via the 1,3Alt conformer is only slightly higher in energy; the rate-limiting steps are the Paco $\rightarrow 1,3 \mathrm{Alt} \rightarrow$ Paco' legs, whose transition-state energy relative to the Cone ground state is $E^{4}$ pot $=4.0 \mathrm{kcal} / \mathrm{mol}$. To search for a concerted reaction (i.e. without the Paco intermediate), a direct refinement of the Cone - Cone' conversion was done with the Cone conformer taken as reactant and the Cone' conformer as product. The resulting pathway was found not to be concerted, but to proceed via the Paco and 1,2Alt intermediates.

Because there are four ways for a Cone conformer to convert into a Paco conformer (by flipping any one of the four benzyl rings), each with a potential energy barrier of $\Delta E^{*}$ pot $=3.8 \mathrm{kcal} /$ 


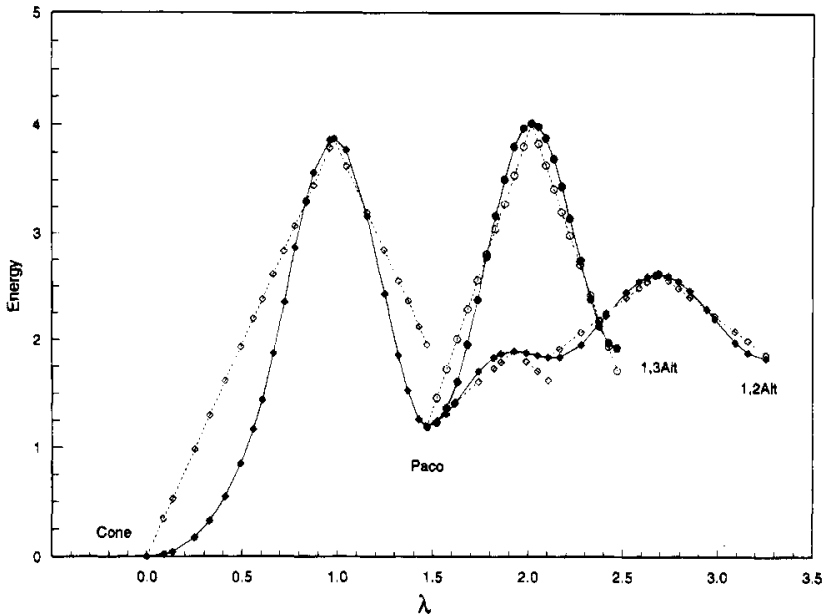

Figure 2. Energy profile (solid line, $\mathrm{kcal} / \mathrm{mol}$ ) and Hammond correlation (dashed line) for the ring-flipping isomerization reactions in compound 3a.
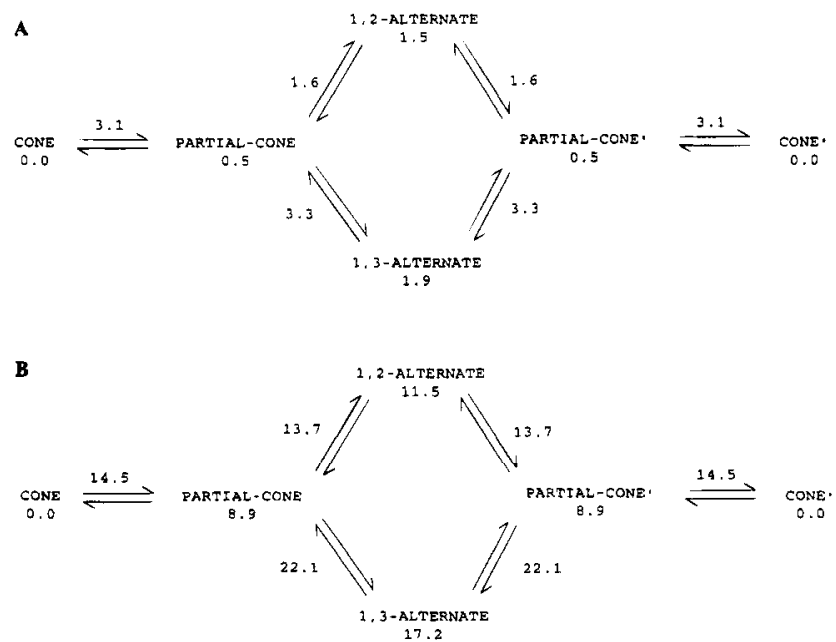

Figure 3. Connectivity chart and pathways for the Cone $\rightarrow$ Cone $^{\prime}$ conversion: (A) cyclophane 3a, (B) calix[4]arene 1a. The numbers are the energies $\left(E_{\text {conf }}\right)$ of the stable conformers or $E_{\text {conf }}^{+}$of the transition state of the reactions (in $\mathrm{kcal} / \mathrm{mol}$, corrected for conformational degeneracy, see text and Tables 1 and 3).

mol, the energy of activation of the Cone $\rightarrow$ Paco transition corrected for this conformational entropy is $\Delta E_{\text {conf }}^{\ddagger}=\Delta E^{4}$ pot $-k T \ln 4$. At $-30^{\circ} \mathrm{C}, \Delta E_{\text {conf }}^{+}=3.1 \mathrm{kcal} / \mathrm{mol}$, which is below the upper limit of $\Delta G^{\ddagger}<5.9 \mathrm{kcal} / \mathrm{mol}$ deduced from ${ }^{1} \mathrm{H}$ NMR measurements for the Cone $\rightarrow$ Cone' conversion. ${ }^{19 d}$ These results agree with the experimental observations that conformational interconversions in [1 4 ]metacyclophanes are very fast. ${ }^{19}$ $\Delta E^{4}$ conf is computed for all reactions listed in Table 3 by comparing the conformational degeneracy of the saddle points to the degeneracy of the ground state (see Discussion).

(ii) Stepwise Interconversion in 1a. For compound 1a, both stepwise (involving a single phenyl ring flip at a time) and direct (involving more than one ring-flip) interconversion pathways were calculated. The stepwise Cone $\rightarrow$ Inverted Cone (Cone') reaction was investigated by individually refining the Cone $\rightarrow$ Paco, Paco $\rightarrow$ 1,2Alt, and Paco $\rightarrow$ 1,3Alt paths. The direct Cone $\rightarrow 1,2 \mathrm{Alt}$, Cone $\rightarrow 1,3 \mathrm{Alt}$, and Cone $\rightarrow$ Cone' paths were also refined. The direct Cone $\rightarrow 1,2 \mathrm{Alt}$ path has the same saddle points as the stepwise Cone $\rightarrow$ Paco $\rightarrow 1,2 \mathrm{Alt}$ pathway. Similarly, the direct Cone $\rightarrow 1,3$ Alt path proceeds via the stepwise Cone $\rightarrow$ Paco $\rightarrow 1,3 \mathrm{Alt}$ pathway. The direct Cone $\rightarrow$ Cone' path also proceeds via a stepwise pathway, so that all interconversions in 1a can be broken down into three reaction steps, whose transition-state energies are listed in Table 3. The corresponding potential energy profiles along these reactions

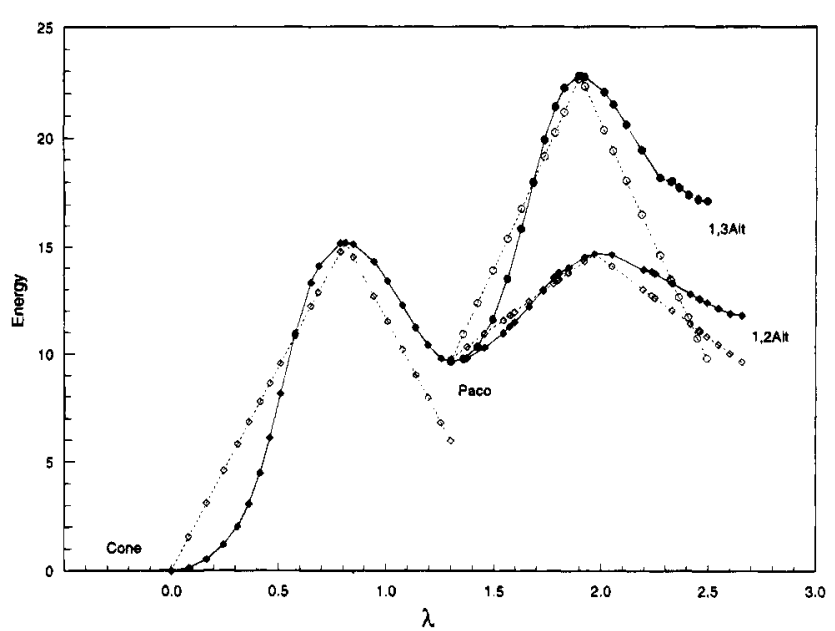

Figure 4. Energy profile (solid line, $\mathrm{kcal} / \mathrm{mol}$ ) and Hammond correlation $H_{i}$ (dashed line, see text) for the stepwise ring-flipping isomerization reactions in compound 1a. Shown are the Cone $\rightarrow \mathrm{Paco}$, $\mathrm{Paco} \rightarrow 1,2 \mathrm{Alt}$, and Paco $\rightarrow 1,3 \mathrm{Alt}$ paths. $\lambda$ is the curvilinear reaction coordinate, in $\AA$ (see Methods section).

are shown in Figure 4. Concerted paths, with two or more rings flipping simultaneously, were not found. Figure 3B shows the possible pathways for a Cone $\rightarrow$ Cone' interconversion. The overall rate-limiting step (as defined by the highest energy barrier) of the Cone $\rightarrow$ Cone' interconversion is the Cone $\rightarrow$ Paco transition, with an activation barrier of $\Delta E_{\text {pot }}^{\dagger}=15.2 \mathrm{kcal}$ mol. The pathway then proceeds via the $1,2 \mathrm{Alt}$ conformer, which has a much lower barrier than the Paco $\rightarrow 1,3 \mathrm{Alt}$ path. Accounting for the conformational entropy of the Cone $\rightarrow$ Paco transition (see previous section and Discussion), $\Delta E_{\text {conf }}^{*}=14.5$ $\mathrm{kcal} / \mathrm{mol}$, in excellent agreement with the experimental $\Delta H^{\ddagger}$ value of $14.2 \mathrm{kcal} / \mathrm{mol}$ in $\mathrm{CDCl}_{3}$ as determined by ${ }^{1} \mathrm{H}$ NMR for the Cone $\rightarrow$ Cone' interconversion. ${ }^{13 \mathrm{c}}$ Much of the barrier comes from breaking two hydrogen bonds, which amounts to $\Delta E_{\text {elec }}^{+}=9.1 \mathrm{kcal} / \mathrm{mol}$. Most of the remainder of the activation barrier comes from the deformation of some bond angles, such as the $\mathrm{AR}-\mathrm{CH}-\mathrm{AR}$ angles (from $110^{\circ}$ to $120^{\circ}$ ) of the two methylene groups to which the rotating ring is attached, with $\Delta E_{\text {angle }}^{\ddagger}=5.9 \mathrm{kcal} / \mathrm{mol}$. In the transition state, the rotating ring makes an angle of $\sim-20^{\circ}$ with the mean plane of the four methylene carbon atoms, which means that the phenol group has partly passed through the plane of the methylene carbon atoms (Figure 5). During the transition, the opposite phenol ring rotates to be more in plane with the annulus, whereas the other two phenol rings move the other way and become closer to perpendicular to the plane of the methylene groups.

Earlier reaction path calculations have been performed on 1c by forcing internal rotations around an axis going through the two methylene groups attached to the phenolic ring. ${ }^{3}$ This torsion angle was constrained and the rest of the calix[4]arene was relaxed by energy minimization. The resulting energy barriers for the interconversions Cone $\rightarrow$ Paco, Paco $\rightarrow 1,2 \mathrm{Alt}$, and $\mathrm{Paco} \rightarrow 1,3 \mathrm{Alt}$ were $8.1,8.9$, and $9.4 \mathrm{kcal} / \mathrm{mol}$, respectively. The force field used, MM2P, ${ }^{9}$ treated the hydrogen bonds only in a qualitative way, so that lower barriers were obtained even though the optimal path was not followed. The predefined reaction coordinate did not ensure full relaxation during the interconversion and the maxima along this reduced adiabatic path were not resolved to true saddle points.

(iii) Concerted Interconversion in 1a. Investigation of the strength of the hydrogen bonds in calix[4]arenes with IR spectroscopy in $\mathrm{CCl}_{4}$ has suggested that the hydrogen bonding in calix[4]arenes may be cooperative, i.e. the breaking of the first $\mathrm{H}$-bond in the circular array of four $\mathrm{H}$-bonds is more difficult than the breaking of additional H-bonds. This is 
A
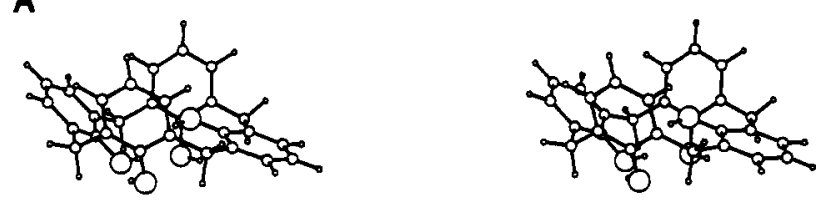

B
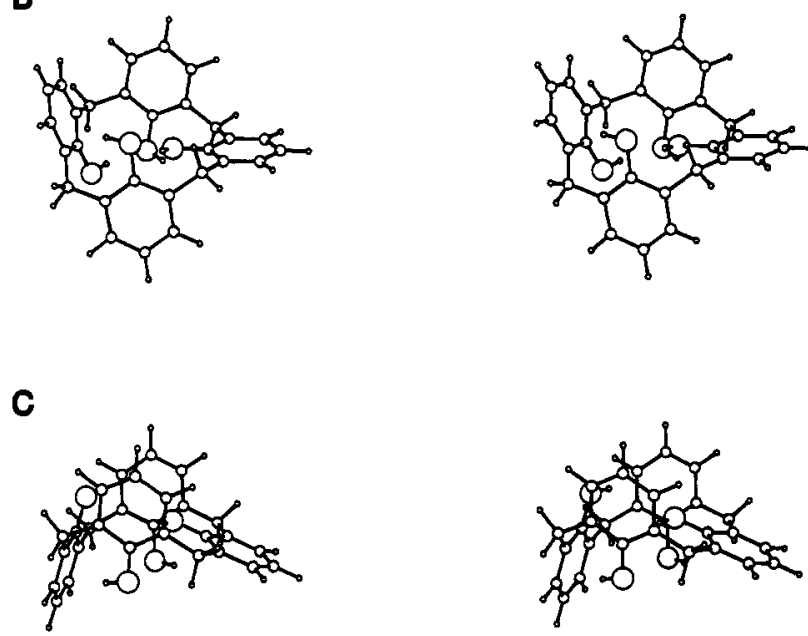

Figure 5. Saddle-point structure (stereo) of the ring-flipping isomerizations in compound 1a: (A) Cone $\rightarrow$ Paco, (B) Paco $\rightarrow$ 1,2Alt, (C) Paco $\rightarrow 1,3 \mathrm{Alt}$. In each case, the converting ring is on the right and is rotating clockwise for the indicated reaction direction.

believed to be caused by polarization of the $\mathrm{O}-\mathrm{H}$ bonds in the circular array. ${ }^{15}$ The polarization effect in 1a was investigated here by adding a charge $\Delta q$ to the hydrogens and $-\Delta q$ to the oxygens of the hydroxyl groups. For every $\Delta q$, the conformers were reoptimized and the direct Cone $\rightarrow 1,2 \mathrm{Alt}$ and Cone $\rightarrow$ 3,1 Alt conversion pathways were refined. In each case, the stepwise pathways through the Paco intermediate become a concerted movement of the phenol rings when $\Delta q \geq 0.35 \mathrm{e}$, as denoted by the presence of a single saddle point instead of two successive saddle points along the path. With $\Delta q=0.35$, resulting in a partial charge of $-0.89 \mathrm{e}$ on $\mathrm{O}$ and $+0.78 \mathrm{e}$ on $\mathrm{H}$, the potential energy of the unique saddle point relative to the reoptimized Cone is $37.4 \mathrm{kcal} / \mathrm{mol}$ for the Cone $\rightarrow 1,2 \mathrm{Alt}$ path and $66.9 \mathrm{kcal} / \mathrm{mol}$ for the Cone $\rightarrow 1,3$ Alt path. The structure of the transition state is respectively 1,2Alt-like and 1,3Alt-like and it is characterized by the preservation of the four hydrogen bonds in a partially distorted circular array, at the cost of considerable distortion of the calix[4]arene framework (Figure 6). The 1,2 $\mathrm{Alt}^{\ddagger}$ conformer more readily accommodates the four hydrogen bonds than the 1,3Alt ${ }^{\ddagger}$ conformer, because two H-bonds are still present in the stable 1,2Alt conformer, whereas the stable 1,3Alt conformer has all four H-bonds broken. This explains why the concerted pathway via the $1,2 \mathrm{Alt}^{\ddagger}$ conformer is much more favorable than that via the $1,3 \mathrm{Alt}^{\ddagger}$ conformer. The value of $\Delta q$ at which the pathway changes from a stepwise pathway to a concerted pathway coincides with the $\Delta q$ at which the Paco conformation becomes a hybrid Paco/1,2Alt conformation (Figure 7). The concerted pathway via the $1,2 \mathrm{Alt}^{*}$ conformer resembles the proposed "continuous-chain" pathway. ${ }^{13 \mathrm{~b}}$ While these results indicate that a "continuous-chain" pathway is in principle possible, it is unlikely because of the unrealistically large partial charges on the hydroxyl groups necessary to obtain it and because the potential energy of the 1,2Alt and the 1,3Alt conformers relative to the Cone conformer increases significantly with $\Delta q$, reaching 35.7 and $66.4 \mathrm{kcal} / \mathrm{mol}$, respectively, when $\Delta q=0.35$, i.e. only 1.7 and $0.5 \mathrm{kcal} / \mathrm{mol}$ less than the respective transition-state
A
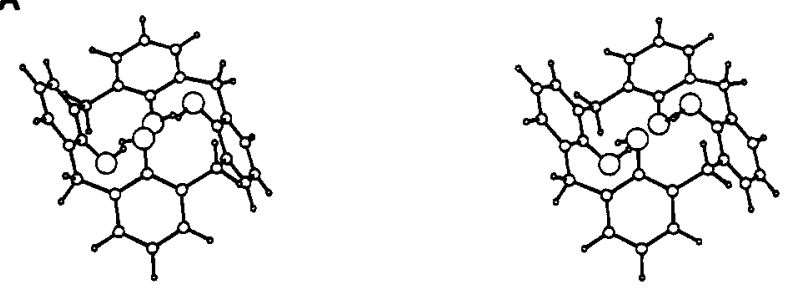

B
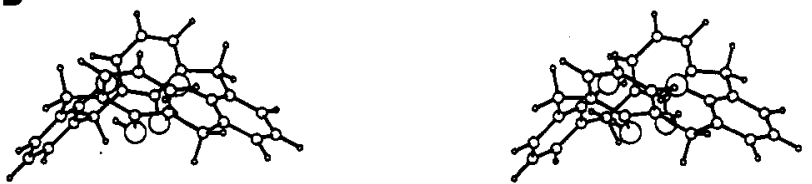

Figure 6. Saddle-point structure (stereo) of concerted ring-flipping in 1a with hydroxyl charge separation increased by $\Delta q=0.35$ e: (A) Paco $\rightarrow 1,2$ Alt, (B) Paco $\rightarrow 1,3$ Alt.
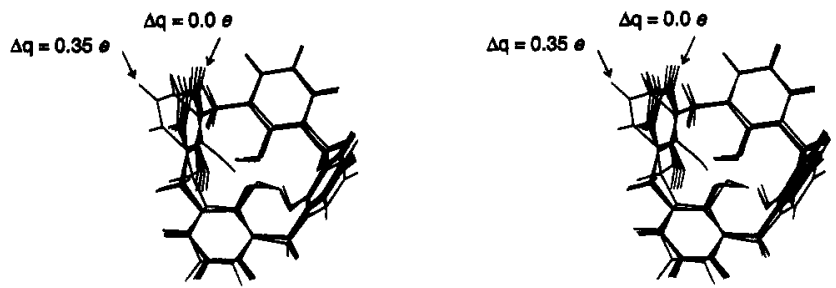

Figure 7. Optimized structures (stereo) of the 1a Paco conformer obtained with increments in the hydroxyl charge separations $\Delta q$ of 0.0 , $0.1,0.2,0.3$ and $0.35 \mathrm{e}$.

Table 4. Potential Energy ( $\mathrm{kcal} / \mathrm{mol})$ of the Transition State in Isomerization Reactions of $\mathbf{2} \mathbf{b}^{a}$

\begin{tabular}{|c|c|c|c|c|c|}
\hline reaction & $E_{\text {coval }}^{*}$ & $E_{\mathrm{vdW}}^{*}$ & $E^{F}$ elec & $E_{\text {pot }}^{F^{\prime}}$ & $\Delta E^{F}{ }_{\text {pot }}^{b}$ \\
\hline $\begin{array}{l}C_{2 v} \text { Cone } \rightarrow C_{2 v} \text { Cone }^{\prime c} \\
\text { methoxy rotations }\end{array}$ & -0.2 & 0.7 & 2.6 & 3.1 & \\
\hline $0000 \sim \mathrm{AAAA} \rightarrow 0000 \sim \mathrm{AABA}$ & -3.4 & 4.3 & 8.8 & 9.7 & 5.9 \\
\hline $0001 \sim \mathrm{AAAA} \rightarrow 0001 \sim \mathrm{AABA}$ & -1 & 2.0 & 7.8 & 8.0 & 8.0 \\
\hline $0011 \sim \mathrm{ABAB}$ & 2.4 & 4.0 & 1.5 & 7.9 & 7.2 \\
\hline $0101 \sim \mathrm{AAAA} \rightarrow 0101 \sim \mathrm{AABA}$ & -1.4 & 1.0 & 8.4 & 8.0 & 7.5 \\
\hline ring-flif & & & & & \\
\hline $0001 \sim \mathrm{AABA} \rightarrow 0000 \sim \mathrm{AABB}$ & 12.7 & 9.0 & -2.1 & 19.6 & \\
\hline $1 \sim$ AABA $\rightarrow 0011 \sim$ AAAA & 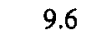 & 8.7 & 1.9 & 20.2 & \\
\hline $0001 \sim \mathrm{BBAA} \rightarrow 0101 \sim \mathrm{BAAA}$ & 10.7 & 9.1 & -1.6 & 18.2 & \\
\hline
\end{tabular}

${ }^{a}$ The reactions listed here are the ones which have the lowest saddlepoint energy for each given type of reaction (such as a methoxy rotation in a Cone, in a Paco, etc.). Energies are relative to the Paco ground state $0001 \sim$ ABAA. See also caption of Tables 1 and $2 .{ }^{b} \Delta E^{*}$ pot is the energy barrier relative to the ground state of the respective characteristic conformer (i.e. Cone, Paco, etc.). ${ }^{c}$ Energies are relative to the $0000 \sim$ AAAA Cone.

energies. Most importantly, the corresponding activation barriers are irreconcilable with the kinetic data from NMR experiments (see previous section). Therefore, our calculations indicate that a concerted mechanism is unrealistic, i.e. the conversion from Cone conformer to inverted Cone conformer in 1 proceeds via a stepwise mechanism with the Paco and 1,2Alt conformers as intermediates (see Figure 3B).

(iv) Interconversions in Calix[4]arene 2b. For the tetramethyl ether $\mathbf{2 b}$ the situation is more complicated because of the many minima that are introduced by the two possible orientations for each methoxy group (see Table 2). The orientation of the methoxy groups affects the energy barriers of the anisole ring rotations, which are large compared to the barriers of the methoxy rotations themselves. The transitionstate potential energies of some methoxy rotations are listed in Table 4 and can be seen to be in the $8-10 \mathrm{kcal} / \mathrm{mol}$ range, whereas the lowest ring rotation transition states are in the 20$24 \mathrm{kcal} / \mathrm{mol}$ range. Taken relative to the ground states of each 

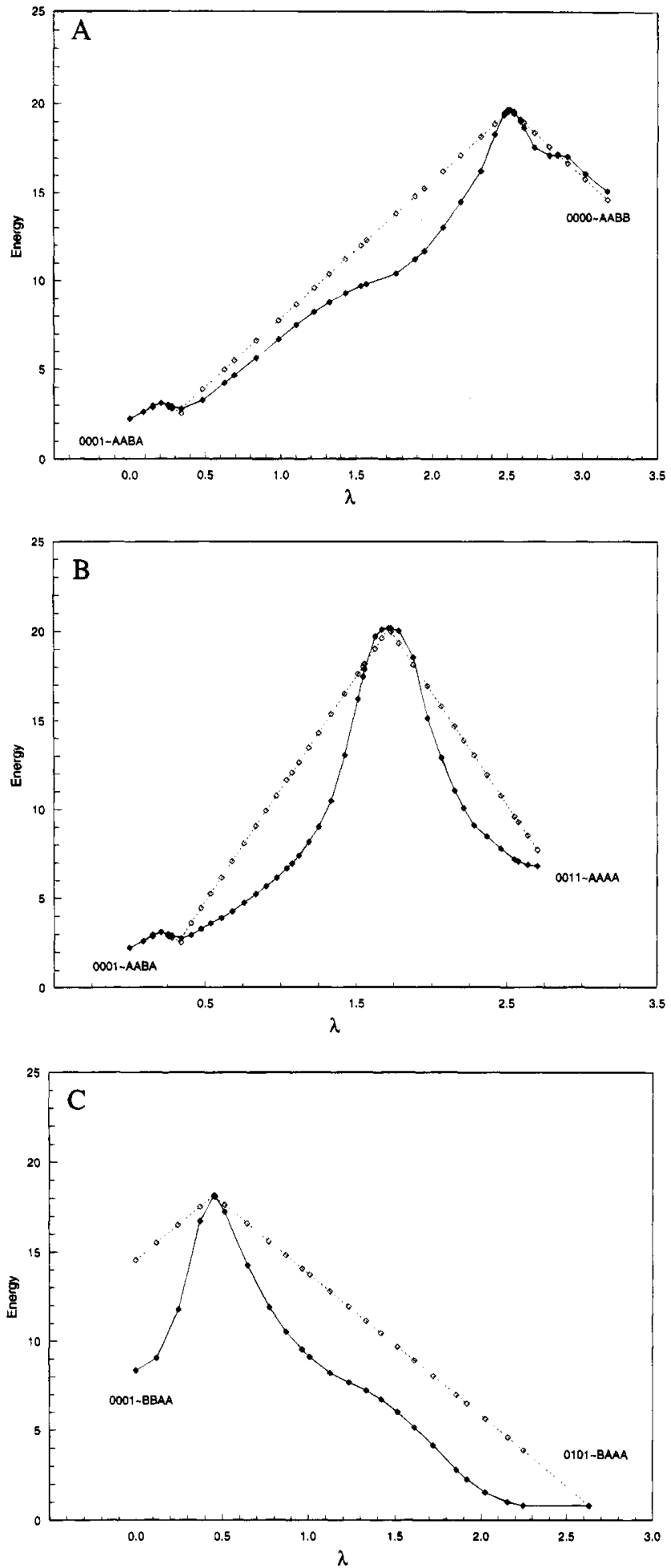

Figure 8. Energy profiles $(\mathrm{kcal} / \mathrm{mol})$ for the $(A)$ Paco $\rightarrow$ Cone, $(B)$ Paco $\rightarrow$ 1,2Alt, (C) Paco $\rightarrow$ 1,3Alt ring-flip conversions of $\mathbf{2 b}$. See the caption of Table 2 for the nomenclature of the conformations.

of the four characteristic conformers of $\mathbf{2 b}$, the activation barriers to methoxy rotation are only 6-8 kcal/mol (Table 4). For example, the $0000 \sim A A A A \rightarrow 0000 \sim A A B A$ reaction has a barrier of $\Delta E_{\text {pot }}^{\ddagger}=5.9 \mathrm{kcal} / \mathrm{mol}$ relative to the Cone ground state. A search for the preferred ring interconversion pathway cannot be limited to the conformational transitions between the reactant and product conformers with the most stable methoxy orientation, because paths for ring conversion with lower overall transition-state energy might connect characteristic conformers whose methoxy groups are not in the ground-state orientation. The conversion paths from the Paco conformer to the Cone, $1,2 \mathrm{Alt}$, and 1,3Alt conformations were determined for all

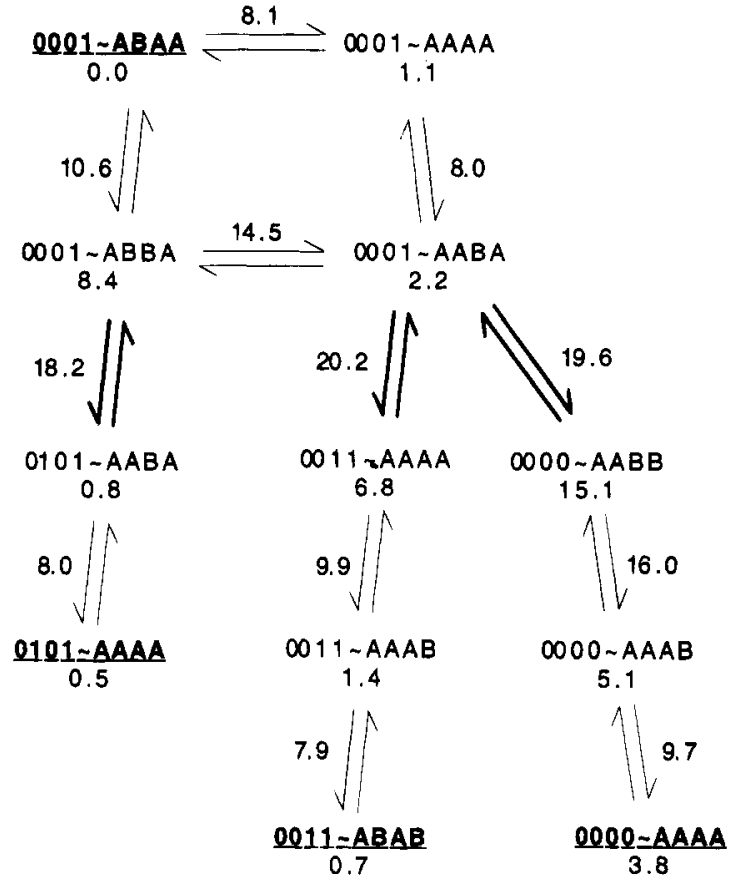

Figure 9. Connectivity chart for calix[4]arene $\mathbf{2 b}$. Shown are the lowest energy pathways connecting the ground states of the four characteristic conformers, i.e. $0001 \sim A B A A, \quad 0101 \sim A A A A$, $0011 \sim A B A B$, and $0000 \sim A A A A$ (see footnote of Table 2 for an explanation of the conformation names). Thick arrows: flipping of the phenyl ring. Thin arrows: methoxy rotations. The numbers are the energies $E_{\text {pot }}$ (in $\mathrm{kcal} / \mathrm{mol}$ ) of the stable conformers or $E_{\text {pot }}^{+}$of the transition state of the reactions (see Tables 2 and 4). Notice that for all transitions from one ground state to another, two or more methoxy rotations are necessary.

combinations of reactant and product methoxy orientations, for a total of 228 reactions.

The Paco $\rightarrow$ Cone conversion with the lowest saddle point potential energy of $19.6 \mathrm{kcal} / \mathrm{mol}$ is found with $0001 \sim \mathrm{AABA}$ as the Paco reactant (Table 4), which is $2.2 \mathrm{kcal} / \mathrm{mol}$ higher than the 0001 ABAA Paco ground state (Table 2). The Paco $\rightarrow$ Cone conversion directly from the Paco ground state yields a saddle point whose potential energy is slightly higher at 19.8 $\mathrm{kcal} / \mathrm{mol}$. The transition from the Paco ground state to $0001 \sim A A B A$ has a barrier of only $8.1 \mathrm{kcal} / \mathrm{mol}$ and therefore is not the rate-limiting step of the $\mathrm{Paco} \rightarrow$ Cone ring-flip. The situation is similar for the Paco $\rightarrow 1,2 \mathrm{Alt}$ conversion, where the lowest transition state is also achieved when $0001 \sim A A B A$ is the Paco reactant, and for the $\mathrm{Paco} \rightarrow 1,3 \mathrm{Alt}$ transition, which proceeds from the $0001 \sim B B A A$ Paco state. The smallest activation barriers relative to the Paco ground state are then $19.6,20.2$, and $18.2 \mathrm{kcal} / \mathrm{mol}$ respectively for the $\mathrm{Paco} \rightarrow$ Cone, Paco $\rightarrow 1,2$ Alt and Paco $\rightarrow$ 1,3Alt conversions. The corresponding potential energy profiles are shown in Figure 8, parts $\mathrm{A}, \mathrm{B}$, and $\mathrm{C}$. The pathways connecting the four ground states of the characteristic conformers via methoxy rotation and anisole ring conversion are shown in Figure 9. In all cases, the activation energy for ring conversion is dominated by an increase of about $9 \mathrm{kcal} / \mathrm{mol}$ in van der Waals energy and an increase in bond stretch and bond angle energy of $3-6 \mathrm{kcal} / \mathrm{mol}$. The electrostatic contribution to the barriers is smaller than in calix[4]arene 1a and comparable to that found in compound 3a (See Table 3), due to the lack of strong $\mathrm{H}$-bonds. The conformations of the saddle points are shown in Figure 10.

The $C_{4 v}$ symmetric Cone of $\mathbf{2 b}$ has been proposed ${ }^{2}$ to be the saddle point of the interchange of two equivalent $C_{2 v}$ symmetric Cone conformations. In the $C_{2 v}$ form, the planes of two facing anisole rings are almost parallel to each other ("pinched") and 
A
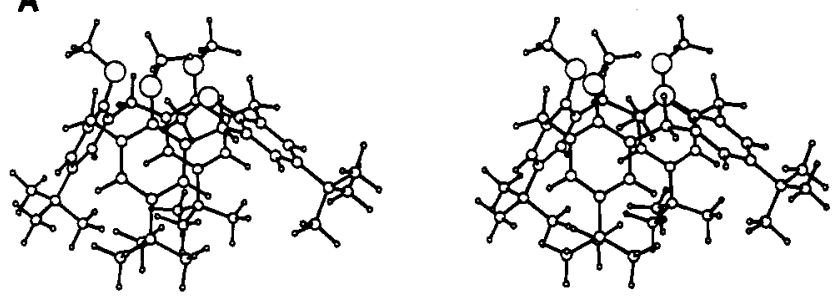

B
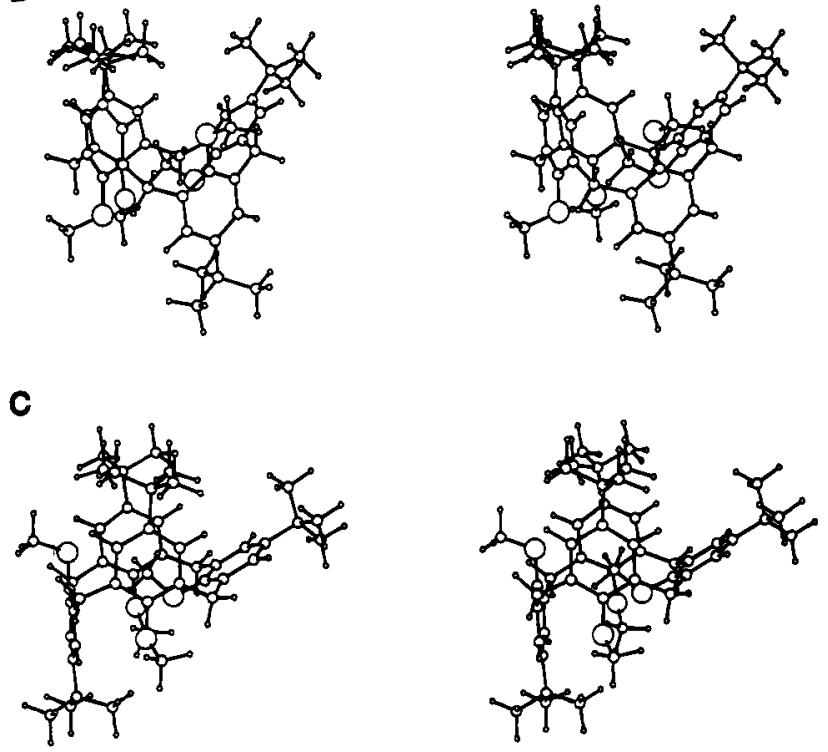

Figure 10. Saddle-point structures (stereo) of the ring-flipping isomerizations in compound $2 \mathrm{~b}:(\mathrm{A}) 0001 \sim A A B A \rightarrow 0000 \sim A A B B$, (B) 0001 AABA $\rightarrow 0011 \sim A A A A$, (C) 0001 BBAA $\rightarrow$ 0101-BAAA. In each case, the converting ring is on the right and is rotating clockwise for the indicated reaction direction. See footnote of Table 2 for an explanation of the conformation names.

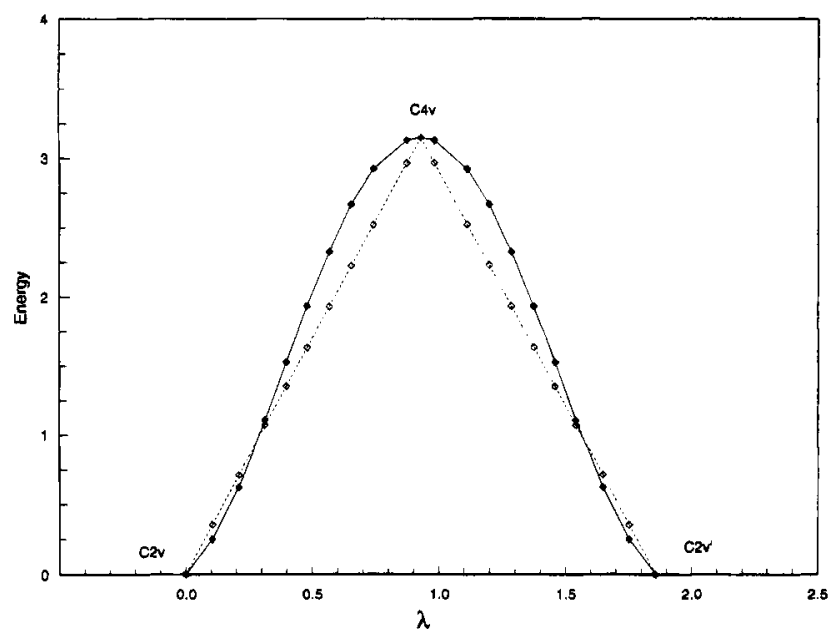

Figure 11. Energy profile (solid line, $\mathrm{kcal} / \mathrm{mol}$ ) and Hammond correlation (dashed line) for the conversion from one $C_{2 v}$ Cone to the other in $\mathbf{2 b}$.

orthogonal to the annulus while the other two anisole rings are more coplanar with the annulus, unlike the $C_{4 v}$ Cone which has the four rings at the same angle relative to the plane of the annulus. We have calculated the transition from one $0000 \sim A A A A$ $C_{2 v}$ Cone to the other (Figure 11). The saddle point is only 3.1 $\mathrm{kcal} / \mathrm{mol}$ higher in potential energy than the $C_{2 \nu}$ Cone and is indeed a $C_{4 v}$ Cone. A comparable result was obtained by constrained energy minimization using the AMBER 3.0 force field. ${ }^{2} \quad C_{2 v} \rightarrow C_{2 v}{ }^{\prime}$ transitions have been observed during molecular dynamics simulations ${ }^{31}$ of lower rim substituted derivatives of 2. The type of lower ring substituent affects the propensity for the $C_{2 v}$ form. ${ }^{2}$

\section{Discussion}

The distribution ${ }^{7,4 a}$ of the conformations of $2 \mathrm{~b}$ as determined with ${ }^{1} \mathrm{H}$ NMR in $\mathrm{CDCl}_{3}$ at $-30^{\circ} \mathrm{C}$ is $85 \%$ Paco, $8 \% 1,2 \mathrm{Alt}$, $4 \%$ Cone, and $3 \% 1,3 \mathrm{Alt}$. The accuracy in these particular NMR spectra is expected to be around $2 \%$ (absolute). The Boltzmann weighted probability of finding compound $\mathbf{2 b}$ in state $x$, corrected for the conformational degeneracy and neglecting vibrational effects on relative populations (vibrational and rotational contributions to the free energy will be presented elsewhere), is given by ${ }^{32}$

$$
p(x)=\frac{\sum_{i \subset x} n_{i} \mathrm{e}^{-E_{i} / k T}}{\Omega}
$$

where $n_{i}$ is the degeneracy of conformer $i$ and $E_{i}$ is the potential energy (both given in Table 2 ). $\Omega$ is the partition function

$$
\Omega=\sum_{\text {all } j} n_{j} \mathrm{e}^{-E j / k T}
$$

For example, there are two possible $A A A A$ Cones for compound $2 \mathrm{~b}, 0000 \sim A A A A$ and $1111 \sim A A A A$, so the degeneracy of that conformer is $n=2$. With the data in Table 2, $p(\mathrm{Paco})=63.3 \%, p(1,2 \mathrm{Alt})=18.4 \%, p(1,3 \mathrm{Alt})=18.3 \%$, and $p$ (Cone $)=0.006 \%$ at $-30{ }^{\circ} \mathrm{C}$. The Paco state is correctly predicted as the most probable conformation, but its calculated probability is somewhat lower than the experimental one. Also, the order of the abundance of the Cone and 1,3Alt forms is inverted.

If the relative energy differences due to methoxy rotation are assumed to be correct within each characteristic conformer of 2b and a constant correction term $\Delta E_{x}$ is added to the potential energy (as given in Table 2) of every conformer in the characteristic state $x$, then the exact experimental distribution is obtained for $\Delta E_{\text {Paco }} \equiv 0.0, \Delta E_{1,2 \mathrm{Alt}}=+0.54 \mathrm{kcal} / \mathrm{mol}, \Delta E_{1,3 \mathrm{Alt}}$ $=+1.0 \mathrm{kcal} / \mathrm{mol}$, and $\Delta E_{\text {Cone }}=-3.0 \mathrm{kcal} / \mathrm{mol}$. If only the lowest conformer of each type is considered, the result is $\Delta E_{\mathrm{Paco}}$ $\equiv 0.0, \Delta E_{1,2 \mathrm{Alt}}=+0.44 \mathrm{kcal} / \mathrm{mol}, \Delta E_{1,3 \mathrm{Alt}}=+0.43 \mathrm{kcal} / \mathrm{mol}$, and $\Delta E_{\text {Cone }}=-3.0 \mathrm{kcal} / \mathrm{mol}$. With the MM3 force field, the following relative stabilities have been found: ${ }^{4} \mathrm{Paco}>1,3 \mathrm{Alt}$ $\approx$ Cone $>1.2 \mathrm{Alt}$, i.e. the ranking of the Cone was consistent with experimetnal data, but the 1,3Alt and 1,2Alt were inverted. A study ${ }^{2}$ with the AMBER 3.0 force field resulted in 1,3Alt > Paco $>$ Cone $>1,2$ Alt. Quantitatively correct values are difficult to achieve, due to the complex balance of forces, particularly between covalent and electrostatic terms (see Table 2).

The Paco conformation has a high field position $(\delta=1.99$ ppm) for one of its three methoxy signals in the ${ }^{1} \mathrm{H}$ NMR spectrum of $\mathbf{2 b}$ in $\mathrm{CDCl}_{3},{ }^{7}$ indicating that one strongly shielded methoxy group is pointing inwards. This agrees with two of the three most stable Paco forms found here, $0001 \sim A B A A$ and $0001 \sim A A A B$ (Table 2), which both have one methoxy pointing inward. The Cone has one single low field methoxy signal $(\delta$ $=3.83 \mathrm{ppm}$ ), indicating that the four unshielded methoxy groups are pointing outwards. This is consistent with the most stable Cone conformer, which has all methoxy groups pointing out (0000 AAAA in Table 2). In the 1,2Alt and 1,3Alt conformers, the four methoxy groups show one single intermediate field

(31) Guilbaud, P.; Varnek, A.; Wipff, G. J. Am. Chem. Soc. 1993, 115 $8298-8312$

(32) McQuarrie, D. A. Statistical Mechanics; Harper \& Row: New York, 1976. 


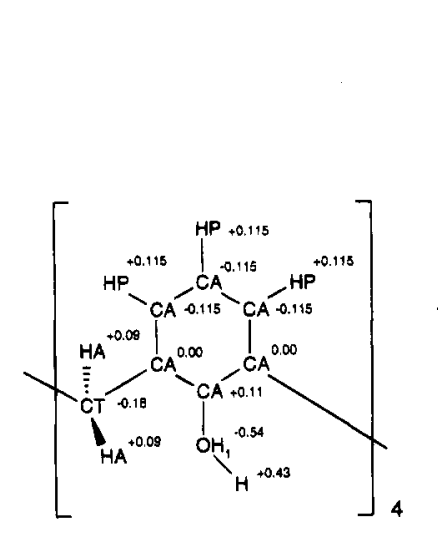

$1 \mathrm{a}$

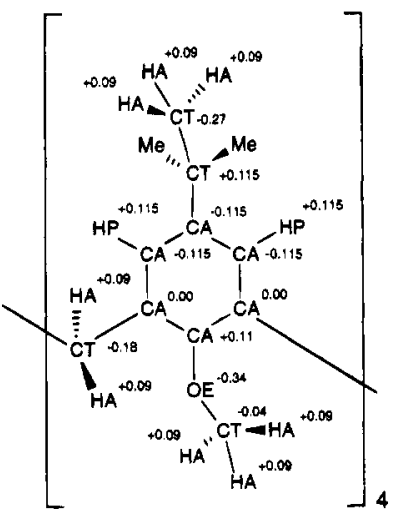

2b

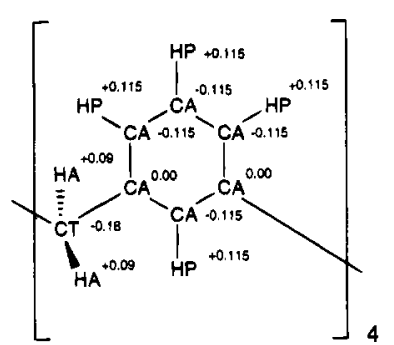

$3 \mathbf{a}$

Figure 12. Atom types and partial charges of $\mathbf{1 a}, \mathbf{2 b}$, and $\mathbf{3 a}$.

Table 5. van der Waals Parameters

\begin{tabular}{lcclcc}
\hline $\begin{array}{l}\text { atom } \\
\text { type }\end{array}$ & $\begin{array}{c}E_{\min } \\
\left(\mathrm{kcal} \mathrm{mol}^{-1}\right)\end{array}$ & $\begin{array}{c}R_{\min } / 2 \\
(\AA)\end{array}$ & $\begin{array}{c}\text { atom } \\
\text { type }\end{array}$ & $\begin{array}{c}E_{\min } \\
\left(\mathrm{kcal} \mathrm{mol}^{-1}\right)\end{array}$ & $\begin{array}{c}R_{\min } / 2 \\
(\AA)\end{array}$ \\
\hline $\mathrm{CA}$ & -0.0700 & 1.9924 & $\mathrm{HP}$ & -0.0300 & 1.3582 \\
$\mathrm{CT}$ & -0.1562 & 1.8000 & $\mathrm{H}$ & -0.0460 & 0.2245 \\
$\mathrm{HA}$ & -0.0078 & 1.468 & $\mathrm{OE}$ & -0.1200 & 1.7700 \\
$\mathrm{OH} 1$ & -0.1521 & 1.7700 & & & \\
\hline
\end{tabular}

signal ( $\delta=2.99 \mathrm{ppm}$ for the 1,2Alt conformer and $\delta=2.87$ ppm for the 1,3Alt conformer). This means that either the four methoxy groups are pointing inward and have intermediate shielding or there is fast exchange between the strongly shielded inward and the unshielded outward orientations. From the calculations, having four methoxy groups pointing inward is very unfavorable. The $1,3 \mathrm{Alt}$ is only able to accommodate all four methoxy groups pointing inwards at a cost of $12.9 \mathrm{kcal} /$ mol relative to the all-out 1,3Alt conformer. The all-inward conformation of 1,2Alt is unstable. This suggests that in both the 1,2Alt and the 1,3Alt conformers there is a fast exchange between conformations with methoxy groups pointing inward and outward. For example, the most populated 1,2Alt conformer $(A B A B)$ has two methoxy groups in and two out. If the methoxy groups are rapidly interchanging $(A B A B \leftrightarrow B A B A)$, a single intermediate field signal is expected. This is consistent with the calculations, which show that the methoxy rotations in the 1,2Alt and 1,3Alt conformers have low transition barriers relative to their respective ground states $\left(\Delta E^{+}{ }_{\text {pot }}\right.$ in Table 4). The rate of interconversion between two species at a temperature where their signals have just coalesced in the spectrum (the coalescence temperature) can be estimated from the separation of the two signals (in $\mathrm{Hz}$ ) at a low temperature where the two species are not exchanging. An upper limit to the barrier for methoxy rotation can be estimated for the 1,2Alt and 1,3Alt conformers, whose inward and outward methoxy signals have coalesced. If one takes $1.84 \mathrm{ppm}$ as an upper bound to the separation between the inward and outward methoxy signals (from the observed values of the methoxy signals, $1.99 \mathrm{ppm}$ inward in Paco and 3.83 ppm outward in Cone), this corresponds to $1104 \mathrm{~Hz}$ at $600 \mathrm{MHz}$. Assuming Arrhenius kinetics, equal population of the two states, and $-30^{\circ} \mathrm{C}$ as the coalescence temperature, the energy barrier to methoxy rotation is $\Delta E^{+} \leq$ $10.7 \mathrm{kcal} / \mathrm{mol}$. Our calculated barriers for methoxy rotation $\left(\Delta E^{+}{ }_{\text {pot }}\right.$ in Table 4$)$ are in agreement with this limiting value.

The ${ }^{1} \mathbf{H}$ NMR data for the Cone conformation of $\mathbf{2 b}$ are consistent with either a $C_{4 v}$ symmetric Cone or the average structure resulting form the rapid interconversion between the two possible $C_{2 \nu}$ Cone conformers, in which the $C_{4 \nu}$ Cone is the transition state. ${ }^{2}$ The optimized geometry of the $\mathbf{2 b}$ Cone has $C_{2 v}$ symmetry ("pinched Cone", see Results section). We found the $C_{4 v}$ Cone to be the saddle point in the interconversion
Table 6. Bonded Parameters

\begin{tabular}{|c|c|c|c|c|}
\hline bond & \multicolumn{2}{|c|}{$K_{\mathrm{b}}\left(\mathrm{kcal} \mathrm{mol}^{-1} \AA^{-2}\right)$} & \multicolumn{2}{|r|}{$r_{0}(\AA)$} \\
\hline $\mathrm{CA}-\mathrm{OE}$ & \multicolumn{2}{|c|}{296.70} & \multicolumn{2}{|r|}{1.450} \\
\hline $\mathrm{CT}-\mathrm{OE}$ & \multicolumn{2}{|c|}{296.70} & \multicolumn{2}{|r|}{1.450} \\
\hline $\mathrm{CA}-\mathrm{CA}$ & \multicolumn{2}{|c|}{305.00} & \multicolumn{2}{|r|}{1.375} \\
\hline $\mathrm{CT}-\mathrm{CA}$ & \multicolumn{2}{|c|}{230.00} & \multicolumn{2}{|r|}{1.490} \\
\hline $\mathrm{OH} 1-\mathrm{CA}$ & \multicolumn{2}{|c|}{334.30} & \multirow{2}{*}{\multicolumn{2}{|c|}{1.411}} \\
\hline $\mathrm{OH} 1-\mathrm{H}$ & \multicolumn{2}{|c|}{545.00} & $\begin{array}{l}0.960 \\
080\end{array}$ & \\
\hline $\mathrm{HP}-\mathrm{CA}$ & \multicolumn{2}{|c|}{340.00} & \multirow{2}{*}{\multicolumn{2}{|c|}{$\begin{array}{l}1.080 \\
1.531\end{array}$}} \\
\hline $\mathrm{CT}-\mathrm{CT}$ & & & \\
\hline $\mathrm{HA}-\mathrm{CT}$ & 317.1 & & \multicolumn{2}{|r|}{1.111} \\
\hline angle/Urey-Bradley & $\begin{array}{c}K_{\theta}(\mathrm{kcal} \\
\left.\mathrm{mol}^{-1} \operatorname{Rad}^{-2}\right)\end{array}$ & $\begin{array}{c}\theta_{0} \\
(\mathrm{deg})\end{array}$ & $\begin{array}{l}F(\mathrm{kca} \\
\left.\mathrm{mol}^{-1}\right)\end{array}$ & $l_{0}(\AA)$ \\
\hline $\mathrm{CA}-\mathrm{CT}-\mathrm{CA}$ & 52.000 & 109.47 & & \\
\hline $\mathrm{CA}-\mathrm{CA}-\mathrm{OE}$ & 45.200 & 120.00 & & \\
\hline $\mathrm{CA}-\mathrm{OE}-\mathrm{CT}$ & 110.00 & 109.7 & & \\
\hline $\mathrm{OE}-\mathrm{CT}-\mathrm{HA}$ & 45.200 & 107.24 & & \\
\hline $\mathrm{H}-\mathrm{OH} 1-\mathrm{CA}$ & 65.000 & 108.00 & & \\
\hline $\mathrm{OH} 1-\mathrm{CA}-\mathrm{CA}$ & 45.200 & 120.00 & & \\
\hline $\mathrm{CA}-\mathrm{CA}-\mathrm{CA}$ & 40.000 & 120.00 & 35.00 & 2.4162 \\
\hline $\mathrm{CT}-\mathrm{CA}-\mathrm{CA}$ & 45.800 & 122.30 & & \\
\hline $\mathrm{CT}-\mathrm{CT}-\mathrm{CA}$ & 51.800 & 107.50 & & \\
\hline $\mathrm{HA}-\mathrm{CT}-\mathrm{CT}$ & 33.430 & 110.10 & 22.53 & 2.1790 \\
\hline $\mathrm{HA}-\mathrm{CT}-\mathrm{CA}$ & 49.300 & 107.50 & & \\
\hline $\mathrm{CT}-\mathrm{CT}-\mathrm{CT}$ & 58.350 & 113.50 & 11.16 & 2.5610 \\
\hline $\mathrm{HP}-\mathrm{CA}-\mathrm{CA}$ & 30.000 & 120.00 & 22.00 & 2.1525 \\
\hline $\mathrm{HA}-\mathrm{CT}-\mathrm{HA}$ & 36.000 & 108.40 & 5.20 & 1.8020 \\
\hline dihedral angle & $K_{\phi}$ (kcal & $\left.\mathrm{ol}^{-1}\right)$ & $n$ & $\phi(\mathrm{deg})$ \\
\hline $\mathrm{OE}-\mathrm{CA}-\mathrm{CA}-\mathrm{CT}$ & 3.1 & & 2 & 180.00 \\
\hline $\mathrm{CA}-\mathrm{CA}-\mathrm{OE}-\mathrm{CT}$ & 1.4 & & 2 & 180.00 \\
\hline $\mathrm{OE}-\mathrm{CA}-\mathrm{CA}-\mathrm{CA}$ & 3.1 & & 2 & 180.00 \\
\hline $\mathrm{OE}-\mathrm{CA}-\mathrm{CA}-\mathrm{CT}$ & 3.1 & & 2 & 180.00 \\
\hline $\mathrm{OE}-\mathrm{CA}-\mathrm{CA}-\mathrm{HP}$ & 3.1 & & 2 & 180.00 \\
\hline $\mathrm{HP}-\mathrm{CA}-\mathrm{CA}-\mathrm{HP}$ & 2.4 & & 2 & 180.00 \\
\hline $\mathrm{OH} 1-\mathrm{CA}-\mathrm{CA}-\mathrm{CT}$ & 3.1 & & 2 & 180.00 \\
\hline $\mathrm{H}-\mathrm{OH} 1-\mathrm{CA}-\mathrm{CA}$ & 0.9 & & 2 & 180.00 \\
\hline $\mathrm{OH} 1-\mathrm{CA}-\mathrm{CA}-\mathrm{CA}$ & 3.1 & & 2 & 180.00 \\
\hline $\mathrm{HA}-\mathrm{CT}-\mathrm{OE}-\mathrm{CA}$ & 0.1 & & 3 & 0.00 \\
\hline $\mathrm{CA}-\mathrm{CA}-\mathrm{CA}-\mathrm{CA}$ & 3.1 & & 2 & 180.00 \\
\hline $\mathrm{CT}-\mathrm{CA}-\mathrm{CA}-\mathrm{CA}$ & 3.1 & & 2 & 180.00 \\
\hline $\mathrm{HP}-\mathrm{CA}-\mathrm{CA}-\mathrm{CA}$ & 4.2 & & 2 & 180.00 \\
\hline $\mathrm{HP}-\mathrm{CA}-\mathrm{CA}-\mathrm{CT}$ & 4.2 & & 2 & 180.00 \\
\hline $\mathrm{CT}-\mathrm{CT}-\mathrm{CA}-\mathrm{CA}$ & 0.2 & & 2 & 180.00 \\
\hline $\mathrm{HA}-\mathrm{CT}-\mathrm{CT}-\mathrm{CA}$ & 0.0 & & 3 & 0.00 \\
\hline $\mathrm{X}-\mathrm{CT}-\mathrm{CT}-\mathrm{X}$ & 0.1 & & 3 & 0.00 \\
\hline $\mathrm{X}-\mathrm{CT}-\mathrm{CA}-\mathrm{X}$ & 0.0 & & 2 & 180.00 \\
\hline
\end{tabular}

from one $C_{2 v}$ Cone to the other, with an activation barrier of $3.1 \mathrm{kcal} / \mathrm{mol}$, which suggests that fast interconversion is occurring.

The 2D EXSY NMR spectra of a calixcrown derivative of 2a, which has two facing rings bridged at the upper rim so that the formation of the 1,2Alt conformer is prevented, have shown that Paco can convert to Cone and to 1,3 Alt conformers. ${ }^{16}$ The 
conversion to the $1,3 \mathrm{Alt}$ conformer is faster than conversion to the Cone conformer. This is in accord with the respective activation barriers of 18.2 and $19.6 \mathrm{kcal} / \mathrm{mol}$ calculated here (see Table 4). Measurements on $2 \mathrm{~b}$ with ${ }^{1} \mathrm{H}$ and 2D EXSY NMR indicate that the conversions from Paco to Cone or to 1,3Alt are faster than the conversion from Paco to the 1,2Alt conformer. ${ }^{7}$ This is also consistent with the higher activation barrier of the Paco $\rightarrow 1,2 \mathrm{Alt}$ path $(20.2 \mathrm{kcal} / \mathrm{mol}$ in Table 4$)$.

The pertinence of the Hammond postulate to interconversion reactions in calix[4]arenes was tested by correlating the rootmean-square (rms) displacement of the atomic positions with the energy of the system (see Methods section). In most cases, the reaction energy profiles (see Figures $2,4,8$, and 11) show an excellent correlation with the change in rms of the atomic positions along the path, indicating that the conformational changes in calix[4]arenes obey the Hammond postulate.

Although no solvent effects were included in the calculations, close agreement has been found between the calculated and experimental $\Delta H^{\ddagger}$ for the Cone $\rightarrow$ inverted-Cone conversion of $1 \mathrm{a}$ in $\mathrm{CDCl}_{3}$. This is not surprising, since the $\Delta G^{\ddagger}$ as determined by ${ }^{1} \mathrm{H}$ NMR is nearly solvent independent. ${ }^{13 \mathrm{~b}}$ In contrast, the conformational distribution of $\mathbf{2} \mathbf{b}$ found by ${ }^{1} \mathrm{H}$ NMR is influenced by the solvent, ${ }^{15}$ mostly changes in the abundance of the Cone form at the cost of the other forms: $5 \%$ Cone in $\mathrm{CDCl}_{3}, 14 \%$ Cone in $\mathrm{CS}_{2}$ and $\mathrm{CCl}_{4}, 18 \%$ Cone in toluene. Explanations for this behavior have been sought either in terms of the polarity of the solvent ${ }^{33}$ or by the inclusion of a solvent molecule in the cavity of the Cone. ${ }^{15,31}$ Solvent polarity cannot explain all the solvent effect data; e.g. the Cone conformer of $\mathbf{2 b}$ is more abundant in $\mathrm{CCl}_{4}$ than in $\mathrm{CDCl}_{3}$, although the latter is the more polar solvent and the Cone is the conformation with the largest dipole moment, which would be expected to be more abundant in a more polar solvent. ${ }^{15}$ More likely, enlargement of the cavity in the tert-butyl-substituted calix[4]arenes allows for complex formation with the solvent. $^{14,17}$

\section{Conclusions}

The energies and conformational transitions of calix[4]arenes $\mathbf{1 a}$ and $\mathbf{2 b}$ and $\left[1_{4}\right]$ metacyclophane $3 \mathbf{a}$ have been studied using the CHARMM molecular mechanics potential with the new parameter set 22. Although these parameters were developed for amino acids, they could be used without modification. The relative stabilities for the four conformations of the three compounds are in good agreement with experimental NMR data. The same is true for the activation barriers of the ring interconversions between the characteristic conformers of $\mathbf{1 a}$, $\mathbf{2 b}$, and $\mathbf{3 a}$ and of the methoxy rotations in $\mathbf{2 b}$. The present study provides detailed information concerning the calculated pathways connecting the various conformers. This was made possible by the CPR algorithm, which has been implemented in the CHARMM program. In the absence of an initial guess for transition intermediates, the method starts with a linear interpolation pathway from the reactant to the product conformation, which is then refined. In nearly every case, this was sufficient to yield the pathway with the lowest activation barrier for the Cone $\rightarrow$ Cone' conversions. Only in 1a did a stepwise refinement of Cone $\rightarrow$ Paco followed by Paco $\rightarrow 1,2 \mathrm{Alt}$ find a lower saddle point than the direct Cone $\rightarrow$ Cone' calculation, which proceeded via the $1,3 \mathrm{Alt}$ intermediate.

The pathways for $\left[1_{4}\right]$ metacyclophane $3 a$ Cone $\rightarrow$ Cone' $^{\prime}$ interconversion show no marked preference for the $1,2 \mathrm{Alt}$ or 1,3Alt intermediate. The structure of the 1a Cone form is close

(33) Iwamoto, K.; Ikeda, A.; Araki, K.; Ilarada, T.; Shinkai, S. Tetrahedron 1993, 49, 9937-9946. to the Cone form of the 3a [14]metacyclophane, indicating that the circular array of $\mathrm{H}$-bonds in $1 \mathrm{a}$ puts little additional strain on the calix[4]arene frame. The most likely Cone $\rightarrow$ Cone' $^{\prime}$ conversion of 1a is along a stepwise Cone $\rightarrow \mathrm{Paco} \rightarrow 1,2 \mathrm{alt} \rightarrow$

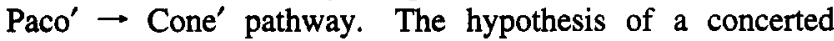
mechanism, in which the four phenol rings of 1 a would corotate to conserve the four H-bonds, is not consistent with the present calculations, as demonstrated by the excessive hydroxyl $\mathrm{O}-\mathrm{H}$ bond polarization necessary to achieve such a mechanism. The relative stability of the $\mathbf{2 b}$ characteristic conformers is affected by the conformational degeneracy of the energy states due to the symmetry of the molecule. Even though the 1,2Alt form $0011 \sim A B A B$ is ranked higher in terms of potential energy than the 1,3Alt form 0101 AAAA, consideration of the conformational degeneracy reveals that the former is more stable than the latter, in accordance with experiment. Similarly, the stability ranking of the 1,3Alt forms $0101 \sim A A A A$ and $0101 \sim A A B A$, differing by their methoxy orientations, is inverted after inclusion of the conformational degeneracy of these structures.

Interconversions between the characteristic conformers of $\mathbf{2 b}$ occur with the Paco form as the key intermediate. The anisole ring interconversions with the lowest absolute transition-state energies are not between the ground states of the respective characteristic conformers but between conformations that are related to their ground states via one (in the case of 1,3Alt), two (in the case of Cone and 1,2Alt), or up to three (in the case of Paco) rotations of the methoxy groups. Rotations of the methoxy moieties have energy barriers well below the energy barriers for anisole ring rotation, explaining why the methoxy hydrogens give a single peak in ${ }^{1} \mathrm{H}$ NMR. The NMR data in favor of a $C_{4 v}$ symmetric Cone, i.e., the aromatic protons appear as one singlet and the protons on the methylene bridges appear as an $\mathrm{ABq}$ system, can be explained by the low barrier between the two stable $C_{2 v}$ forms, which allows fast exchange on the NMR time scale.

The present analysis demonstrates the power of molecular mechanics combined with an efficient and general technique for finding reaction paths to explore in detail the connectivity on potential energy surfaces of complex molecules with multiple conformers.

Note Added in Proof: M. Hosseini pointed out the paper by K. B. Lipkowitz and G. Pearl [J. Org. Chem. 1993, 58, 6729-6736] in which molecular mechanics calculations with different programs for a number of calix[4]arenes were reported. Species $\mathbf{2 b}$ is the only one that was calculated by Lipkowitz and Pearl, as well as in the present paper. In contrast to their results, we find good agreement with experiment. G. Wipff and $M$. Lauterbach (private communication) have obtained energy differences similar to those reported in the present paper; they have also studied the effect of solvent on the energy differences.

Acknowledgment. The work reported here was supported in part by a grant from the National Science Foundation and a gift from Molecular Simulations Inc. to Harvard University.

\section{Appendix}

New molecular mechanics parameters were used for the calix[4]arenes in this study. Figure 12 shows the atom types and their partial charges. The nonbonded van der Waals parameters are given in Table 5 and the bonded parameters in Table 6. 